\title{
Eoxins: A new inflammatory pathway in childhood asthma
}

\author{
Christine Sachs-Olsen, MD, ${ }^{a}$ Marek Sanak, MD, ${ }^{b}$ Astri Maria Lang, MD, ${ }^{a}$ Anna Gielicz, MSc, ${ }^{b}$ Petter Mowinckel, MSc, ${ }^{a}$ \\ Karin Cecilie Lødrup Carlsen, MD, ${ }^{a, c}$ Kai-Håkon Carlsen, MD, ${ }^{\mathbf{a}, \mathbf{c}}$ and Andrzej Szczeklik, MD ${ }^{\mathbf{b}}$ Oslo, Norway, and Krakow, \\ Poland
}

Background: Increased levels of leukotrienes (LTs) in exhaled breath condensate (EBC) are associated with asthma and bronchial hyperresponsiveness (BHR), whereas eicosanoids generated through the 15-lipoxygenase (LO) pathway (15hydroxyeicosatetraenoic acid [HETE] and eoxins) have been less studied.

Objective: We investigated whether metabolites of the 5- and 15-LO pathways in EBC are associated with childhood asthma, asthma severity, and clinical parameters.

Methods: The present study included 131 school-aged children ( 27 children with problematic severe asthma, 80 children with mild-to-moderate asthma, and 24 healthy children) from the Severe Asthma Recognized in Childhood study and 19 children with other nonasthmatic chronic lung diseases. Clinical work-up included spirometry, fractional exhaled nitric oxide

measurements, skin prick testing, and methacholine challenge. Eicosanoids were analyzed in EBC by using mass spectrometry and are reported as concentrations (in picograms per milliliter) and eicosanoid/palmitic acid (PA) ratios.

Results: Eoxin $\mathrm{C}_{4} / \mathrm{PA}$, exin $\mathrm{D}_{4} / \mathrm{PA}$, eoxin $\mathrm{E}_{4} / \mathrm{PA}$, 15-HETE/PA, and $\mathrm{LTC}_{4} / \mathrm{PA}$ ratios were significantly increased in asthmatic versus healthy children. Eoxin $\mathrm{D}_{4} / \mathrm{PA}$ and $\mathrm{LTE}_{4} / \mathrm{PA}$ ratios were also significantly higher in children with BHR. A nonsignificant trend was observed toward higher exin/PA ratios with increasing asthma severity. In contrast to asthma, children with chronic lung disease had the highest 15-HETE/PA, LTC $4 /$ PA, $\mathrm{LTE}_{4} / \mathrm{PA}$, and $\mathrm{LTB}_{4} / \mathrm{PA}$ ratios.

Conclusion: The results point to increased activity of the $15-\mathrm{LO}$ inflammatory pathway in childhood asthma. Mass

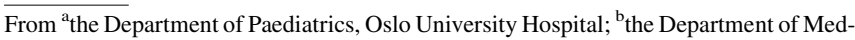
icine, Jagiellonian University Medical College, Krakow; and ${ }^{\mathrm{c}}$ the Faculty of Medicine, University of Oslo

The study was performed within the ORAACLE (Oslo Research Group of Asthma and Allergy in Childhood, the Lung and Environment) and Nordic SEARCH (Severe Asthma Recognized in Childhood) affiliations, both of which are part of the GA ${ }^{2}$ LEN network. The study was supported through the European Economic Area (EEA) financial mechanism. EBC analysis by HPLC-tandem MS has come about as a cooperation project between Norway and Poland sponsored by a Norwegian grant within the framework of the European Community and funds of the Polish Ministry of Science and Higher Education. C. S.-O. has received a research grant from the Kloster foundation, and A. L. has received a research grant from the South Norway Health Region.

Disclosure of potential conflict of interest: C. Sachs-Olsen and A. M. Lang received a fee for scientific lectures from GlaxoSmithKline. M. Sanak, A. Gielicz, and A. Szczeklik have received research support from the European Community and Polish Ministry of Science and Higher Education. K. C. Lødrup Carlsen and K.-H. Carlsen received research support from $\mathrm{GA}^{2} \mathrm{LEN}$. P. Mowinckel has declared that he has no conflict of interest.

Received for publication January 11, 2010; revised June 11, 2010; accepted for publication July 13, 2010.

Reprint requests: Christine Sachs-Olsen, MD, Department of Paediatrics, Oslo University Hospital, Sognsvannsveien 20, NO-0027 Oslo, Norway. E-mail: c.sachs@ online.no.

0091-6749/\$36.00

(C) 2010 American Academy of Allergy, Asthma \& Immunology

doi:10.1016/j.jaci.2010.07.015 spectrometric analyses of EBC demonstrate that increased eoxin levels not only accompany the increased 5-LO product LTC $_{4}$ but are also associated with BHR. These markers might represent a new therapeutic target for asthma treatment. (J Allergy Clin Immunol 2010;126:859-67.)

Key words: Exhaled breath condensate, leukotrienes, 15-hydroxyeicosatetraenoic acid, eoxins, asthma, child

Inflammation is a key element in asthma pathophysiology. ${ }^{1}$ Understanding the underlying inflammatory processes might help tailor individualized anti-inflammatory treatment. Eicosanoids, including prostanoids, leukotrienes (LTs), and lipoxins, are nonspecific products of arachidonic acid catabolism present in a number of inflammatory responses.

Cysteinyl leukotrienes (CysLTs: $\mathrm{LTC}_{4}, \mathrm{LTD}_{4}$, and $\mathrm{LTE}_{4}$ ) and $\mathrm{LTB}_{4}$ are generated through the 5-lipoxygenase (LO) pathway. ${ }^{2}$ Increased levels in exhaled breath condensate (EBC) of asthmatic children are found in some studies ${ }^{3-6}$ but are inconsistently reproduced. The biological role of the 15-LO pathway mediators is less clear, although 15-LO and its major arachidonic metabolite, 15hydroxyeicosatetraenoic acid (15-HETE), might be involved in asthma pathophysiology. IL-4 and IL-13 upregulate 15-LO in human airway epithelial cells and macrophages in vitro. ${ }^{7,8}$ Overexpression of 15-LO, as seen in endobronchial biopsy specimens of asthmatic subjects, ${ }^{9}$ induces chemokine release in cultured airway epithelial cells ${ }^{8}$ and upregulates MUC5AC expression, indicating a putative role in mucin production. ${ }^{10}$ Increased levels of 15-HETE are found in bronchoalveolar lavage (BAL) fluid from persistently wheezing children ${ }^{11}$ and asthmatic adults ${ }^{9}$ and in induced sputum. ${ }^{7}$

The end metabolites of the 15-LO pathway, previously known as 14,15 -LTs and recently renamed eoxins $\mathrm{C}_{4}, \mathrm{D}_{4}$, and $\mathrm{E}_{4}$, have proinflammatory properties. ${ }^{12}$ Eoxins resemble CysLTs but have a different 3 -dimensional structure (Fig 1) ${ }^{13}$ and are formed in eosinophils by means of activation of a different signal transduction pathway. ${ }^{12}$ Eoxin $\mathrm{C}_{4}$ was recently detected in BAL fluid from 3 asthmatic adults, ${ }^{14}$ whereas the eoxins' relationship to childhood asthma is unknown.

The clinical usefulness of EBC in asthma management is unclear. ${ }^{15}$ EBC has an attractive potential, being noninvasive, and might provide more differentiated inflammatory profiles than fractional exhaled nitric oxide $\left(\mathrm{FE}_{\mathrm{NO}}\right) .{ }^{16}$ Although low biomarker concentrations limit the sensitivity of conventional assays, mass spectrometry (MS) offers the advantage of highly sensitive and specific analyses. ${ }^{5,17}$

We aimed primarily to investigate whether metabolites of the 5and 15-LO pathways in EBC are increased in asthmatic subjects. Secondarily, we aimed to assess whether EBC eicosanoids are related to asthma severity or linked to clinical characteristics of childhood asthma, including lung function, bronchial hyperresponsiveness (BHR), $\mathrm{FE}_{\mathrm{NO}}$, and allergic sensitization. 


\author{
Abbreviations used \\ BAL: Bronchoalveolar lavage \\ BHR: Bronchial hyperresponsiveness \\ BMI: Body mass index \\ CysLT: Cysteinyl leukotriene \\ EBC: Exhaled breath condensate \\ ECP: Eosinophilic cationic protein \\ $\mathrm{FEF}_{25-75}$ : Forced expiratory flow during $25 \%$ to $75 \%$ of FVC \\ $\mathrm{FE}_{\mathrm{NO}}$ : Fractional exhaled nitric oxide \\ FVC: Forced vital capacity \\ HETE: Hydroxyeicosatetraenoic acid \\ ICS: Inhaled corticosteroid \\ LO: Lipoxygenase \\ LT: Leukotriene \\ LTRA: Leukotriene receptor antagonist \\ MS: Mass spectrometry \\ PA: Palmitic acid \\ SEARCH: Severe Asthma Recognized in Childhood
}

\section{METHODS}

\section{Study design}

The cross-sectional Severe Asthma Recognized in Childhood (SEARCH) study was performed at Oslo University Hospital, Norway (2006-2007), including children (6-18 years) with problematic severe asthma and agematched children with mild-to-moderate asthma and healthy children. An additional population of 19 children with chronic lung diseases was subsequently included for comparison with asthmatic and healthy children, all recruited during the same time period from the tertiary pediatric unit at Oslo University Hospital.

EBC analyses were performed in the University Department of Medicine, Krakow, Poland (2009). The study was approved by the Regional Committee for Medical Research Ethics and registered in the Norwegian Biobank Registry. Written informed consent was obtained for all participants.

\section{Study population and recruitment}

The present study consisted of the 131 SEARCH children (39\% girls; Table 1 and see Table E1 and Fig E1, which are available in this article's Online Repository at www.jacionline.org) recruited through 4 hospital databases (107 with asthma, 27 of which had problematic severe asthma) or randomly selected healthy children $(n=24)$ through the Norwegian National Registry. Details of patient recruitment are provided in the Methods section of this article's Online Repository at www.jacionline.org. The primary diagnoses of the 19 children with chronic lung disease (9-18 years, 5 girls) were bronchiectasis $(n=6)$, primary ciliary dyskinesia $(n=6)$, bronchopulmonary dysplasia $(\mathrm{n}=3)$, chronic obstructive pulmonary disease $(\mathrm{n}=1)$, chronic atelectasis $(\mathrm{n}=1)$, cystic fibrosis $(\mathrm{n}=1)$, and bronchiolitis obliterans $(\mathrm{n}=1)$. All but one child with chronic lung disease used inhaled corticosteroids (ICSs), and 5 used leukotriene receptor antagonists (LTRAs; Table I).

\section{Inclusion criteria}

Asthma. Asthmatic children required a specialist's diagnosis of asthma plus use of antiasthma treatment, the presence of asthma symptoms within the preceding year, or both. Children with vocal cord dysfunction, cystic fibrosis, bronchiectasis and other chronic lung diseases, immunodeficiencies, or significant neurologic dysfunction were excluded from the SEARCH study.

Problematic severe asthma. ${ }^{18}$. Problematic severe asthma was defined as asthmatic patients who satisfied the following predefined criteria, ascertained by means of a structured interview:

A. Medication at enrollment and during at least 6 of the preceding 12 months (both required):

1. Daily high-dose ( $\geq 800 \mu \mathrm{g} / \mathrm{d}$ budesonide equivalent) ICS treatment

2. Regular long-acting inhaled $\beta_{2}$-agonist, LTRA, or both treatment
B. Asthma symptoms during the preceding year ( $\geq 1$ required):

1. Exacerbations:

a. $\geq 1$ Emergency hospitalization

b. $\geq 1$ Course of doctor-administered oral corticosteroid treatment

c. $\geq 2$ Emergency outpatient visits

d. Exacerbations of asthma more than once a month on average $(\geq 12$ per year)

2. Chronic asthma symptoms (present more than twice a week for at least 3 consecutive months):

a. Asthma symptoms limiting participation in daily activities (including sport and leisure)

b. Nocturnal awakenings because of asthma symptoms

Mild-to-moderate asthma. Mild-to-moderate asthma was defined as all asthmatic patients not meeting the inclusion criteria for problematic severe asthma, irrespective of current asthma treatment and symptom control. Further subclassification according to current regular ICS use was done in some analyses.

Healthy. Healthy subject were those with no doctor's diagnosis of asthma or symptoms indicating obstructive airway disease or other chronic lung disease and no current rhinoconjunctivitis (definition provided in the Methods section of this article's Online Repository), although atopic dermatitis was permitted.

\section{Methods}

Study examinations were performed during 2 to 3 visits, usually within a 2-week period, at least 2 weeks after airway infections or asthma exacerbations. Repeated visits were delayed accordingly, if necessary. A combined patient/parental structured interview included questions on demographic data, atopic disease, current and previous asthma medication, asthma exacerbations, nocturnal and daytime asthma symptoms, and health resource use. Ageand sex-adjusted body mass index (BMI) percentiles were calculated according to published algorithms. ${ }^{19}$ The study protocol also included spirometry, ${ }^{20}$ tests of bronchial responsiveness to methacholine, skin prick tests, $\mathrm{FE}_{\mathrm{NO}}$ measurements, and blood sampling (see the Methods section of this article's Online Repository for more information).

\section{EBC sampling}

EBC samples were collected in accordance with American Thoracic Society/ European Respiratory Society guidelines ${ }^{21}$ by using an ECoScreen Jaeger condensing chamber (GmbH Hoechberg, Germany) with use of a nose clip. Participants performed tidal ventilation for 15 minutes through a mouthpiece connected to the condenser through a 2-way nonrebreathing valve and a salivary trap. Mouth rinse was performed before sampling, and participants were instructed to swallow saliva periodically. EBC samples (1-2 mL) were immediately stored at $-80^{\circ} \mathrm{C}$ in polypropylene microcentrifuge tubes (Eppendorf tubes).

\section{HPLC-tandem MS}

EBC sample preparation is presented in the Methods section of this article's Online Repository. Ten microliters of methanol EBC extract was injected on a reverse phase column (Zorbax Eclipse XDB C-18; Agilent Technologies, Santa Clara, Calif), stabilized thermally $\left(37^{\circ} \mathrm{C}\right)$, and eluted with a gradient consisting of 2 mobile phases, acetonitrile/water/acetic acid (20/80/0.01) and acetonitrile/isopropanol/acetic acid (55/45/0.01), by using the flow rate of $0.11 \mathrm{~mL} / \mathrm{min}$ on HPLC equipped with an autosampler (Shimadzu Sil-2-AC). Analytes were measured by using multiple reactions monitoring mode tandem MS (Qtrap 4000; Applied Biosystems, Foster City, Calif) equipped with an electrospray ion source in 3 separate runs. Positive ionization was used to quantify eoxins, $\mathrm{LTC}_{4}$, and $\mathrm{LTD}_{4}$. Negative ionization was used for $\mathrm{LTE}_{4}$, $\mathrm{LTB}_{4}$, and HETEs. An example of MS analysis of eicosanoids is presented in Fig 2. Palmitic acid (PA) was measured after its derivatization into pentafluorobenzyl ester and purification with thin-layer chromatography by using a gas chromatography negative-ion chemical ionization MS (GC-NICI-MS). 


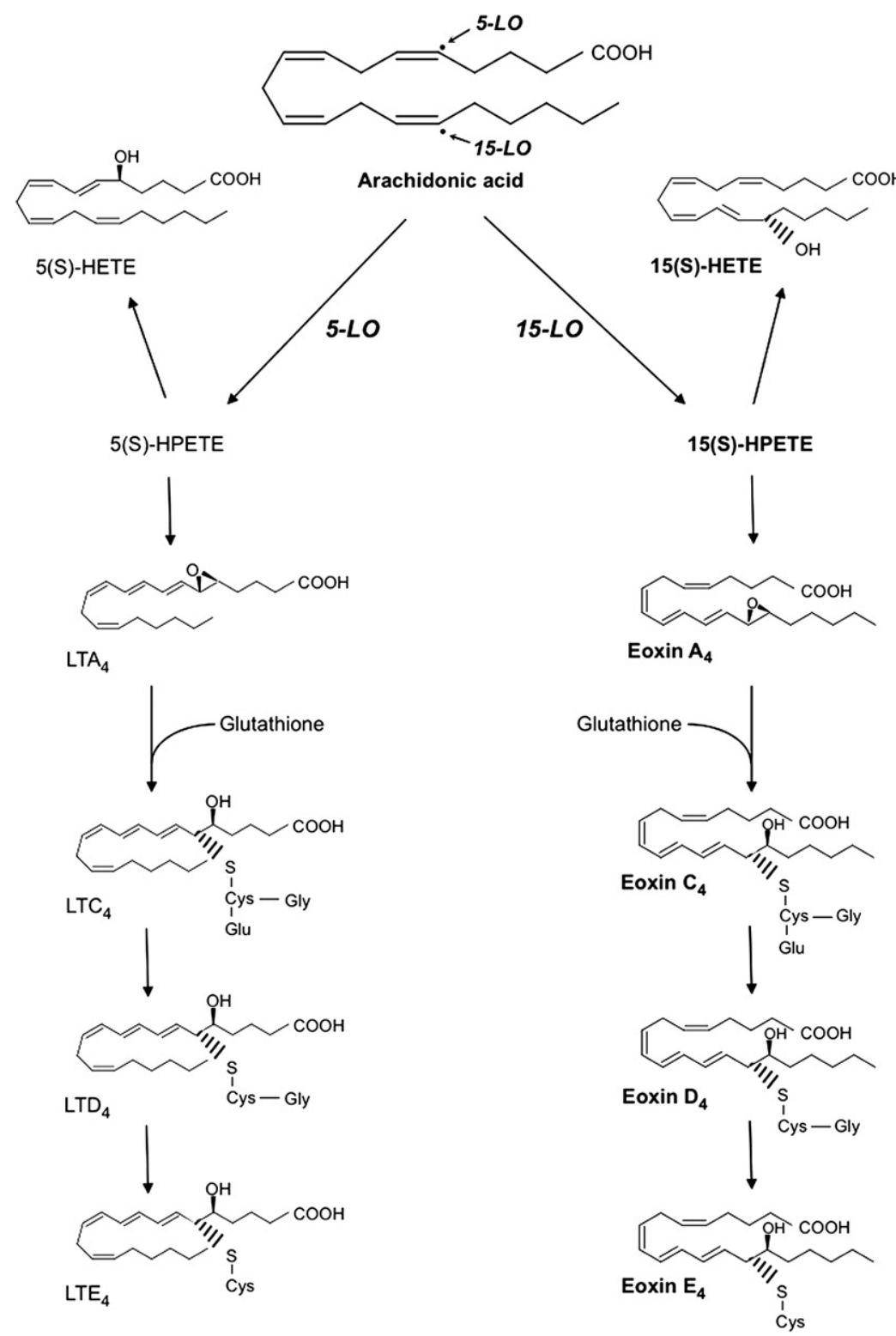

FIG 1. Overview of the biosynthesis of LTs and eoxins.

A single quadrupole instrument (Engine 5989B series II; Hewlett Packard, Palo Alto, Calif) was used in selected ion-monitoring mode. The method currently used has recently been described. ${ }^{22}$

PA was used to adjust for EBC dilution. The concentration of PA was similar in children with other chronic lung diseases and healthy children but decreased with asthma severity in the asthmatic group, possibly enhancing the ratio differences in outcomes between asthmatic and healthy children. Therefore the reported values of EBC eicosanoids include both eicosanoid concentrations (in picograms per milliliter) and eicosanoid/PA ratios.

The MS analyses of the EBC were performed by technicians blinded to all clinical data. No significant time dependency was found for the analyzed eicosanoid levels relative to the patient groups (data not shown).

\section{Statistical analyses}

Results are presented as means (95\% CIs) or counts (percentages). Eicosanoids, eosinophilic cationic protein (ECP), IgE, and $\mathrm{FE}_{\mathrm{NO}}$ measurements are given as geometric means with $95 \%$ CIs. One-way ANOVA was used for comparison of normally distributed or ln-transformed data with the Tukey post-hoc test. The Mann-Whitney test was used for comparisons of nontransformed data; categorical variables were compared by using the Pearson $\chi^{2}$ test or Fisher exact test. Correlation analyses were performed with the Pearson or Spearman tests as appropriate with respect to data distribution.

Analysis of covariance was used to assess the influence of multiple explanatory factors (age, sex, BMI percentile, disease status [asthma or healthy chronic lung disease], $\mathrm{FEV}_{1}$ [percent predicted], forced vital capacity [FVC; percent predicted], forced expiratory flow during $25 \%$ to $75 \%$ of FVC [ $\mathrm{FEF}_{25-75}$; percent predicted], $\mathrm{FEV}_{1} / \mathrm{FVC}$ ratio, allergic sensitization, regular ICS use, and LTRAs) in the last 12 months on eicosanoid concentrations and eicosanoid/PA ratios. A step-down Hosmer procedure was used, excluding variables not significant at the .05 levels. All nonsignificant variables were tested for confounding (ie, a change in the estimate of greater than 25\%). The model was tested for interactions. Least-square means with 95\% CIs were calculated from the final model. Cook's D and Jacknife residuals were used to assess the appropriateness of the models. Statistical analyses were performed with SPSS Version 16.0 software (SPSS, Chicago, Ill) and SAS software (SAS Institute, Inc, Cary, NC). A 2-tailed probability of .05 or less was the threshold for significance in all comparisons. 
TABLE I. Patients' characteristics and clinical data

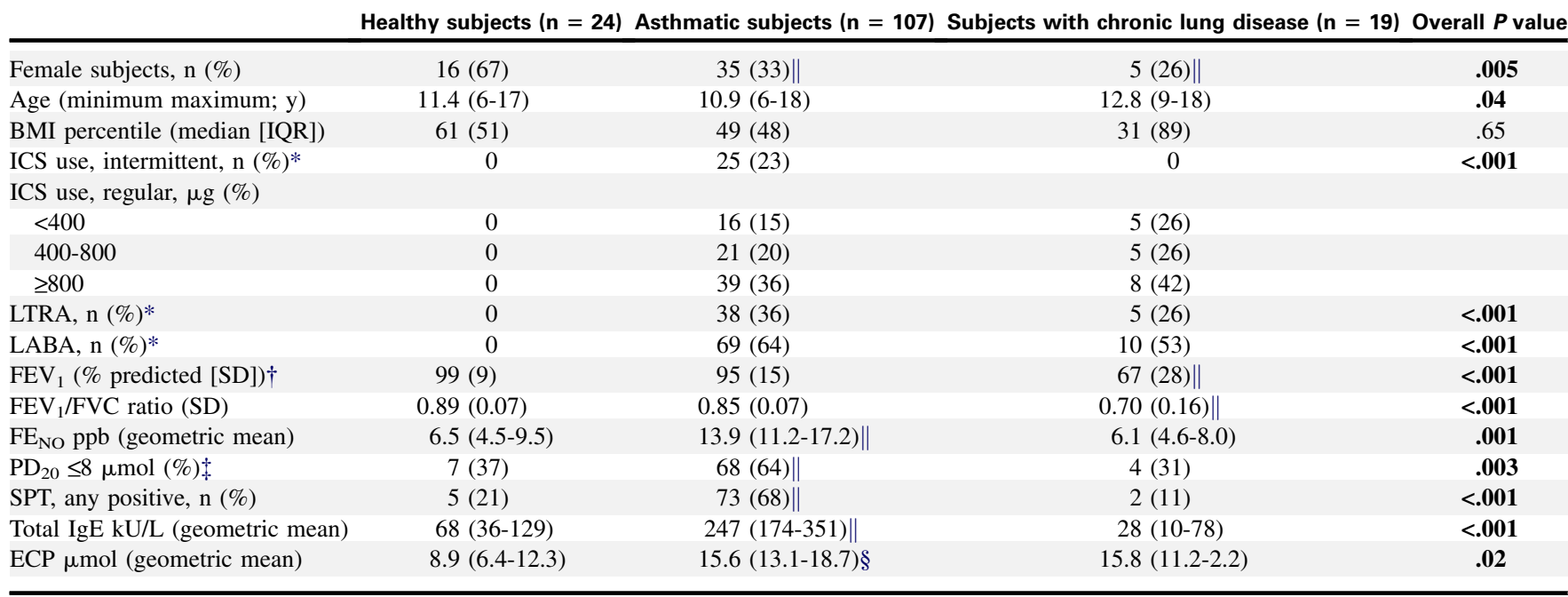

Results are represented as means (95\% CIs) or counts unless otherwise stated. Significance figures are derived by using ANOVA among the 4 populations for continuous variables or $\chi^{2}$ tests for proportions.

$B M I$, body mass index ${ }^{19} ; I Q R$, interquartile range; $S P T$, skin prick test.

*Antiasthma medication within 12 months preceding inclusion to the study and ICS dosage referring to budesonide equivalent daily dose. Intermittent ICS use implies ICS use of short duration during asthma exacerbations and not within 2 weeks before inclusion.

$\dagger$ Reference values by Stanojevic et al. ${ }^{20}$

$\ddagger$ Two children with asthma and 4 children with other chronic lung diseases were too sick to perform $\mathrm{PD}_{20}$ measurement $\left(\mathrm{FEV} \mathrm{C}_{1}<70 \%\right.$ of predicted value).

$\S$ Significant differences at $P<.05$ versus healthy children.

"Significant difference at $P<.01$ versus healthy children.

\section{RESULTS}

Patients' characteristics and clinical data are presented in Table I and by asthma subgroups in Table E1. Compared with healthy children, children with asthma had significantly lower lung function, except $\mathrm{FEV}_{1}$; higher $\mathrm{FE}_{\mathrm{NO}}$; more often $\mathrm{BHR}$ and allergic sensitization; and increased total IgE and ECP levels. A reduced $\mathrm{FEV}_{1} / \mathrm{FVC}$ ratio was the only measurement differentiating problematic severe versus ICS-treated mild-to-moderate asthma (see Table E1). The additional control group of children with other chronic lung diseases had significantly lower lung function than the 2 other groups (Table I).

Eoxin $\mathrm{C}_{4} / \mathrm{PA}$, eoxin $\mathrm{D}_{4} / \mathrm{PA}$, eoxin $\mathrm{E}_{4} / \mathrm{PA}$, and 15 -HETE/PA ratios correlated significantly with $\mathrm{LTC}_{4} / \mathrm{PA}, \mathrm{LTD}_{4} / \mathrm{PA}, \mathrm{LTE}_{4} / \mathrm{PA}$, and 5-HETE/PA ratios, respectively (see Fig E2 and Table E2 in this article's Online Repository at www.jacionline.org).

\section{Eicosanoids and asthma}

Group comparisons demonstrated that asthmatic compared with healthy children had significantly increased concentrations of $\mathrm{LTC}_{4}$ (as the only eicosanoid) and significantly higher eoxin $\mathrm{C}_{4} / \mathrm{PA}$, eoxin $\mathrm{D}_{4} / \mathrm{PA}$, eoxin $\mathrm{E}_{4} / \mathrm{PA}, 15-\mathrm{HETE} / \mathrm{PA}, \mathrm{LTC}_{4} / \mathrm{PA}$, and $\mathrm{LTB}_{4} / \mathrm{PA}$ ratios (Table II).

Eicosanoid concentrations and eicosanoid/PA-ratios in EBC are given for healthy children and children with asthma, as well as other chronic lung diseases, in Table II.

\section{Eicosanoids, sex, age, and BMI $(n=150)$}

No significant sex-based differences were found for eicosanoid concentrations, but boys had higher $\mathrm{LTC}_{4} / \mathrm{PA}$ ratios $(1.9$ vs $1.4 \times$ $\left.10^{-6}, P=.048\right)$ than girls. A similar nonsignificant trend was found for eoxin $\mathrm{D}_{4} / \mathrm{PA}$ ratios $\left(1.7\right.$ vs $\left.1.3 \times 10^{-6}, P=.051\right)$. A weak correlation was found between eoxin $\mathrm{E}_{4}$ concentration and age, $(\rho=-0.20, P=.02)$, whereas $\operatorname{LTD}_{4}(r=-17, P=$ $.04)$ and $\mathrm{LTE}_{4}(r=-0.17, P=.03)$ concentrations correlated weakly with BMI. No significant correlations were found between eicosanoid/PA ratios, age, or BMI.

\section{Eicosanoids, BHR, lung function, allergic sensitization, and inflammatory markers in asthmatic and healthy children}

In children with $\mathrm{BHR}$, eoxin $\mathrm{D}_{4}(P=.007)$, eoxin $\mathrm{E}_{4}(P=.02)$, and $\operatorname{LTE}_{4}(P=.01)$ concentrations were significantly increased, as were eoxin $\mathrm{D}_{4} / \mathrm{PA}(P=.03)$ and $\mathrm{LTE}_{4} / \mathrm{PA}(P=.046)$ ratios compared with values seen in children without BHR. A similar nonsignificant trend was found for eoxin $\mathrm{E}_{4} / \mathrm{PA}$ ratios $(P=.06$, Fig 3 and see Fig E3 in this article's Online Repository at www.jacionline. org). The dose-response slope methacholine $_{\text {correlated significantly }}$ but weakly with the $\mathrm{LTE}_{4} / \mathrm{PA}$ ratio $(r=0.20, P=.03)$. Only the $\mathrm{LTD}_{4} / \mathrm{PA}$ ratio correlated significantly with $\mathrm{FEV}_{1}(r=0.20$, $P=.03$ ), whereas no correlations were found between eicosanoid levels and $\mathrm{FEV}_{1} / \mathrm{FVC}$ ratios. Children with allergic sensitization had higher $\mathrm{LTE}_{4} / \mathrm{PA}$ ratios than those without $(2.7$ vs $2.0 \times$ $10^{-6}, P=.03$ ). No significant correlation was found between eicosanoid levels in $\mathrm{EBC}$ and $\mathrm{FE}_{\mathrm{NO}}$, total IgE, or serum ECP levels.

\section{Multifactor analyses $(n=150)$}

Multifactor analyses on eicosanoid/PA ratios demonstrated asthma to be significantly associated with increased eoxin $\mathrm{E}_{4} / \mathrm{PA}$ and eoxin $\mathrm{D}_{4} / \mathrm{PA}$ ratios in $\mathrm{EBC}$ compared with those seen in healthy children and children with chronic lung diseases. Leastsquares means (with 95\% CIs) of eicosanoid concentrations and eicosanoid/PA ratios are presented in Figs 4 and 5 for the final model of the multifactor analyses (initially including sex, age, 


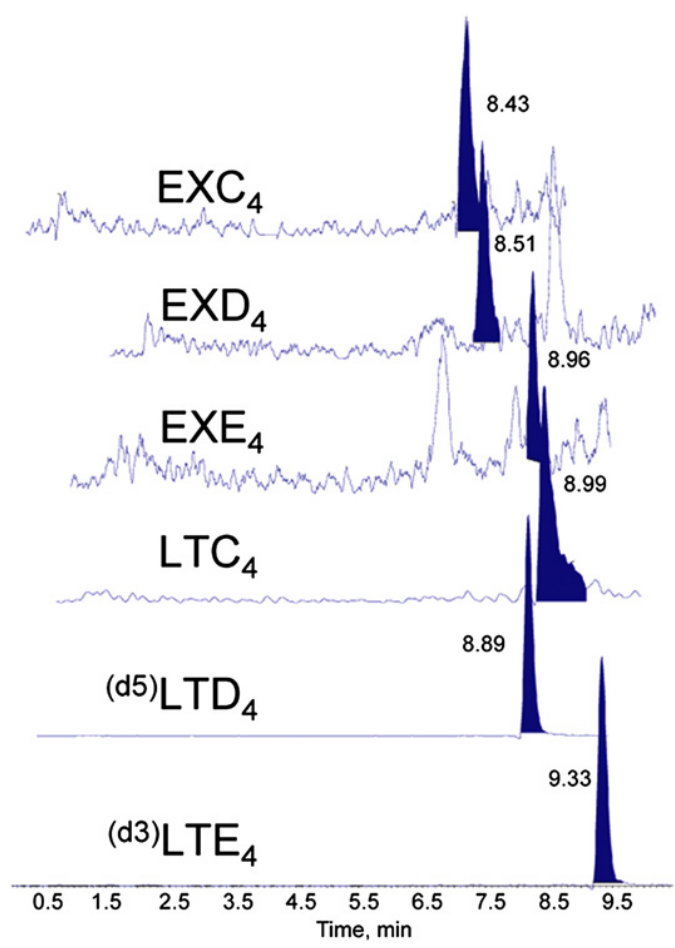

FIG 2. Overlayed HPLC-tandem MS spectrograms of eicosanoids in $1 \mathrm{EBC}$ sample. Eoxins (EXs) $\mathrm{C}_{4}, \mathrm{D}_{4}$, and $\mathrm{E}_{4}$ and CysLTs were measured by using the positive ionization mode and multiple reaction monitoring. Retention times are given aside peaks and verified by using commercially available nondeuterated eoxins (Cayman Chemical Co, Ann Arbor, Mich). Additional details are shown in the Results section of this article's Online Repository.

BMI, lung function, allergic sensitization, and disease status adjusted for LTRA use and regular ICS treatment). Including BHR to methacholine in the initial regression model did not alter the least-squares means and was subsequently excluded from further analyses because of a lack of data in 23 children unable to undergo testing.

Compared with healthy children, EBC from children with asthma had significantly higher $\mathrm{LTC}_{4}$ concentrations $(P<.0001)$, as well as significantly higher eoxin $\mathrm{C}_{4} / \mathrm{PA}(P=.008)$, eoxin $\mathrm{D}_{4} /$ $\mathrm{PA}(P=.005)$, eoxin $\mathrm{E}_{4} / \mathrm{PA}(P=.007), 15-\mathrm{HETE} / \mathrm{PA}(P=.006)$, and $\mathrm{LTC}_{4} / \mathrm{PA}(P=.0004)$ ratios.

Subsequent analyses comparing EBC from children with asthma versus other chronic lung diseases demonstrated significantly higher eoxin $\mathrm{D}_{4} / \mathrm{PA}$ and eoxin $\mathrm{E}_{4} / \mathrm{PA}$ ratios but lower concentrations of eoxin $\mathrm{C}_{4}, 15-\mathrm{HETE}, \mathrm{LTC}_{4}, \mathrm{LTD}_{4}, \mathrm{LTE}_{4}$, and $\mathrm{LTB}_{4}$, as well as lower 15-HETE/PA, $\mathrm{LTC}_{4} / \mathrm{PA}, \mathrm{LTE}_{4} / \mathrm{PA}$, and $\mathrm{LTB}_{4} / \mathrm{PA}$ ratios in asthmatic subjects. Overall, children with other chronic lung diseases had different patterns of eicosanoids in EBC compared with those seen in both asthmatic and healthy children, with significantly higher concentrations of eoxin $\mathrm{C}_{4}$, 15-HETE, $\mathrm{LTC}_{4}, \mathrm{LTD}_{4}, \mathrm{LTE}_{4}$, and $\mathrm{LTB}_{4}$, as well as 15-HETE/PA, LTC ${ }_{4} /$ $\mathrm{PA}, \mathrm{LTE}_{4} / \mathrm{PA}$, and $\mathrm{LTB}_{4} / \mathrm{PA}$ ratios. Group comparisons (ANOVA analyses) showed similar results (see the Results section of this article's Online Repository).

Lung function measures were inconsistently associated with eicosanoids. Although $\mathrm{FEV}_{1}$ and $\mathrm{FEF}_{25-75}$ were positively associated with $\mathrm{LTB}_{4} / \mathrm{PA}(P=.04)$ and 15 -HETE/PA $(P=.006)$ ratios, respectively, FVC was negatively associated with both $\mathrm{LTB}_{4}$ concentrations and PA ratios, (both $P=.04$ ) but positively associated with $\mathrm{LTD}_{4}(P=.01)$ concentrations. An inverse association was found for $\mathrm{FEV}_{1} / \mathrm{FVC}$ and $\mathrm{LTB}_{4} / \mathrm{PA}$ ratios $(P=.03)$.

Allergic sensitization was associated with increased $\mathrm{LTE}_{4}$ concentrations $(P=.01)$ and $\mathrm{LTE}_{4} / \mathrm{PA}$ ratios $(P=.04)$ and $\mathrm{LTB}_{4}$ concentrations $(P=.04)$. Age was associated with decreased concentrations of eoxin $\mathrm{C}_{4}(P=.05)$ and $\operatorname{LTD}_{4}(P=.01)$, and BMI was associated with decreased $\mathrm{LTD}_{4}$ concentrations $(P=$ .002). LTRA use was not significantly associated with eicosanoid concentrations in $\mathrm{EBC}$ but with increased eoxin $\mathrm{E}_{4} / \mathrm{PA}(P=.008)$ and $\mathrm{LTE}_{4} / \mathrm{PA}(P=.01)$ ratios, whereas regular ICS treatment was associated with decreased $\mathrm{LTE}_{4}$ concentrations and $\mathrm{LTE}_{4} / \mathrm{PA}$ ratios $(P=.02)$.

\section{Eicosanoid/PA ratios and asthma severity subgroups}

Eoxin/PA ratios within asthma subgroups and healthy children are presented in Fig E4 (available in this article's Online Repository at www.jacionline.org), and background data on eoxin concentrations and eoxin/PA ratios in the asthma subgroups are provided in Table E3 (available in this article's Online Repository at www.jacionline.org). Although eoxin/PA ratios were highest in patients with problematic severe asthma, differences compared with all other asthmatic children did not reach statistical significance (eoxin $\mathrm{C}_{4}$ : 1.0 vs $0.8 \times 10^{-6}, P=.54$; eoxin $\mathrm{D}_{4}$ : 2.3 vs $1.7 \times 10^{-6}, P=.10$; and eoxin $\mathrm{E}_{4}: 5.1$ vs $3.9 \times 10^{-6}, P=$ $.31)$. Of the SEARCH children, all 10 subjects with the highest levels of 3 or 4 of the eoxin/PA, 15-HETE/PA, or both ratios had asthma (4 problematic severe), 7 used regular ICSs, 5 used LTRAs, and only 1 of the 10 had a negative $\mathrm{PD}_{20}$ methacholine challenge test.

The $\mathrm{LTC}_{4} / \mathrm{PA}$ ratio was significantly increased in children with problematic severe asthma $\left(2.0 \times 10^{-6}[95 \% \mathrm{CI}, 1.3-2.9 \times\right.$ $\left.\left.10^{-6}\right], P=.008\right)$ and in children with mild-to-moderate asthma with $\left(1.8 \times 10^{-6}\left[95 \% \mathrm{CI}, 1.4-2.3 \times 10^{-6}\right], P=.007\right)$ and without $\left(1.6 \times 10^{-6}\left[95 \% \mathrm{CI}, 1.1-2.3 \times 10^{-6}\right], P=.048\right)$ regular ICS use compared with healthy children $\left(0.8 \times 10^{-6}\right.$ [95\% CI, $\left.0.5-1.2] \times 10^{-6}\right)$

\section{DISCUSSION}

The present cross-sectional study, using MS methodology, is the first to demonstrate the presence of eoxins and 15-HETE, inflammatory metabolites of the 15-LO pathway, in EBC and their association with childhood asthma and BHR.

The significantly increased PA ratios of all 15-LO pathway metabolites (15-HETE/PA, eoxin $\mathrm{C}_{4} / \mathrm{PA}$, eoxin $\mathrm{D}_{4} / \mathrm{PA}$, and eoxin $\mathrm{E}_{4} / \mathrm{PA}$ ratios) in asthmatic compared with healthy children and increased eoxin $\mathrm{D}_{4}$ and $\mathrm{E}_{4}$ concentrations in children with BHR (Fig 3) suggest that these metabolites are involved in asthma inflammation in children. Moreover, to substantiate the likelihood that these were in fact related to asthma, we added a second control group of children with other chronic lung diseases. The multivariate analyses demonstrated different eicosanoid patterns in EBC of children with asthma versus those with other chronic lung disease or healthy children (Figs 4 and 5), showing eoxin $\mathrm{D}_{4} / \mathrm{PA}$ and eoxin $\mathrm{E}_{4} / \mathrm{PA}$ ratios to be significantly increased in asthmatic children, whereas eoxin $\mathrm{C}_{4} / \mathrm{PA}$ and 15-HETE/PA ratios were highest in children with chronic lung diseases (Fig 4).

To our knowledge, eoxins have not previously been described in children. Our results are, however, supported by adult studies detecting eoxin $\mathrm{C}_{4}$ (but not eoxins $\mathrm{D}_{4}$ or $\mathrm{E}_{4}$ ) in $\mathrm{BAL}$ fluid of 

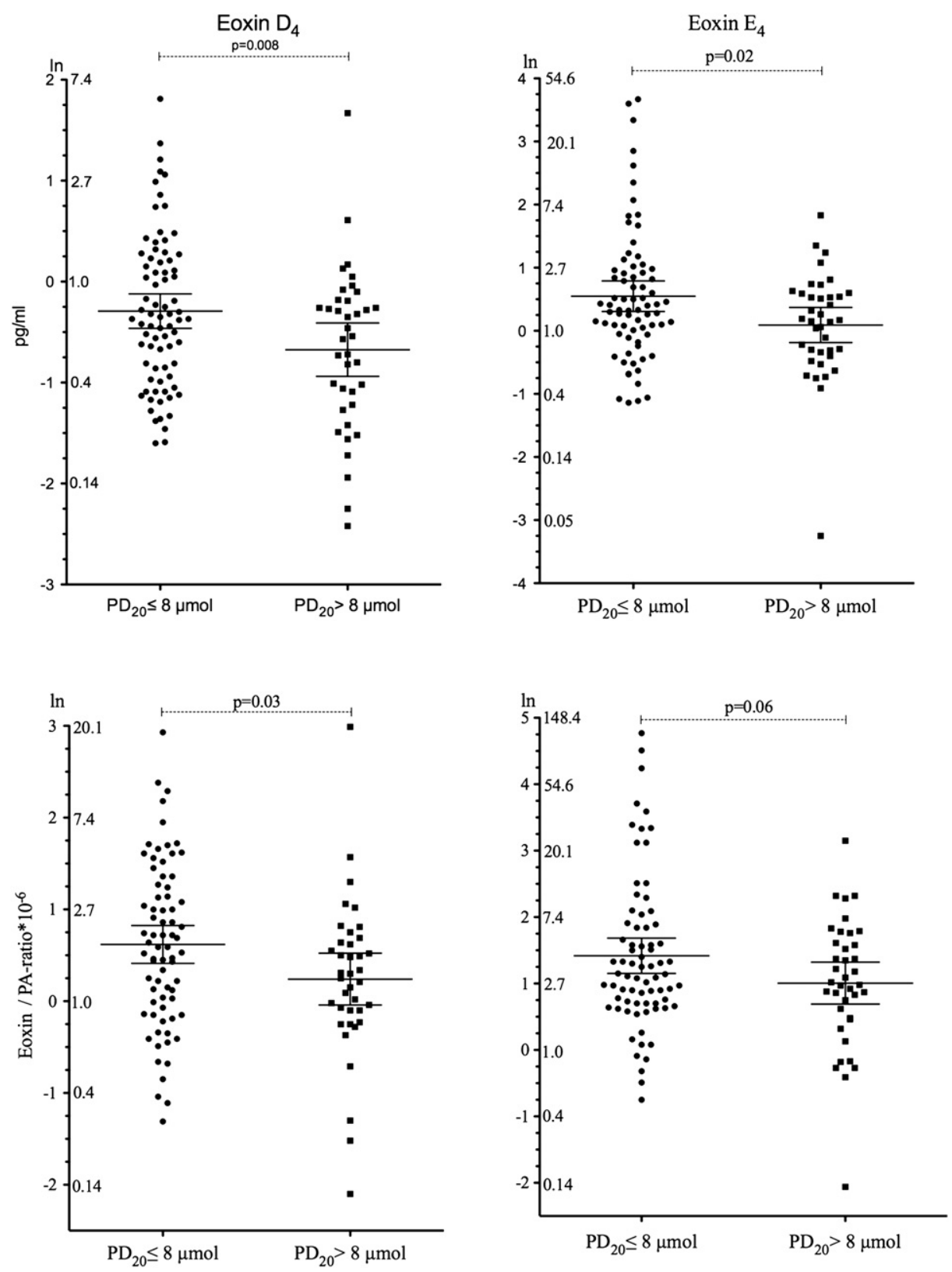

FIG 3. Eoxins $D_{4}$ and $E_{4}$ concentrations and $P A$ ratios (eicosanoid/PA $\times 10^{-6}$ ) in children with $B H R$ to methacholine $\left(\mathrm{PD}_{20} \leq 8 \mu \mathrm{mol}\right.$ methacholine). Values are given as natural logarithms and back-transformed values (geometric means with $95 \% \mathrm{Cls}$ ).

subjects with various respiratory diseases, including asthma. ${ }^{14}$ 15-HETE has also been found to correlate with increasing asthma severity and subbasement membrane thickness. ${ }^{9}$ Biological plausibility of the $15-\mathrm{LO}$ pathway being involved in respiratory inflammation is supported by a study demonstrating that mice deficient in 12/15-LO (the analog to human 15-LO-1) had attenuated allergic inflammation compared with that seen in wild-type mice. ${ }^{23}$

The present study suggests involvement of a new pathway in asthmatic airway inflammation in children. This might pose an alternative explanation for the lack of an LTRA treatment response in many asthmatic children, ${ }^{24,25}$ as well as suggesting a new pathway for the development of new anti-inflammatory drugs for childhood asthma.
Significantly increased $\mathrm{LTC}_{4} / \mathrm{PA}$ ratios in asthmatic children is in line with previous studies on CysLTs,,${ }^{3,4,6,26}$ yet separate detection of $\mathrm{LTC}_{4}$ (or $\mathrm{LTD}_{4}$ ) was not performed in these studies. In the present compared with previous pediatric studies, ${ }^{5,27,28}$ asthma status was not significantly associated with $\mathrm{LTE}_{4}\left(\right.$ or $\left.\mathrm{LTB}_{4}\right)$. Because most previous reports on CysLTs in childhood asthma have used enzyme immunoassay, ${ }^{3,4,6,26-28}$ direct comparisons with our study are difficult. Somewhat surprisingly, EBC of children with other chronic lung diseases had significantly increased $\mathrm{LTC}_{4} / \mathrm{PA}$, $\mathrm{LTE}_{4} / \mathrm{PA}$, and $\mathrm{LTB}_{4} / \mathrm{PA}$ ratios, as well as increased concentrations of all LTs, compared with those seen in asthmatic and healthy children (Fig 5). However, the present study was not designed to investigate the role of eicosanoids in a wide spectrum of lung diseases, although this clearly warrants further study. 

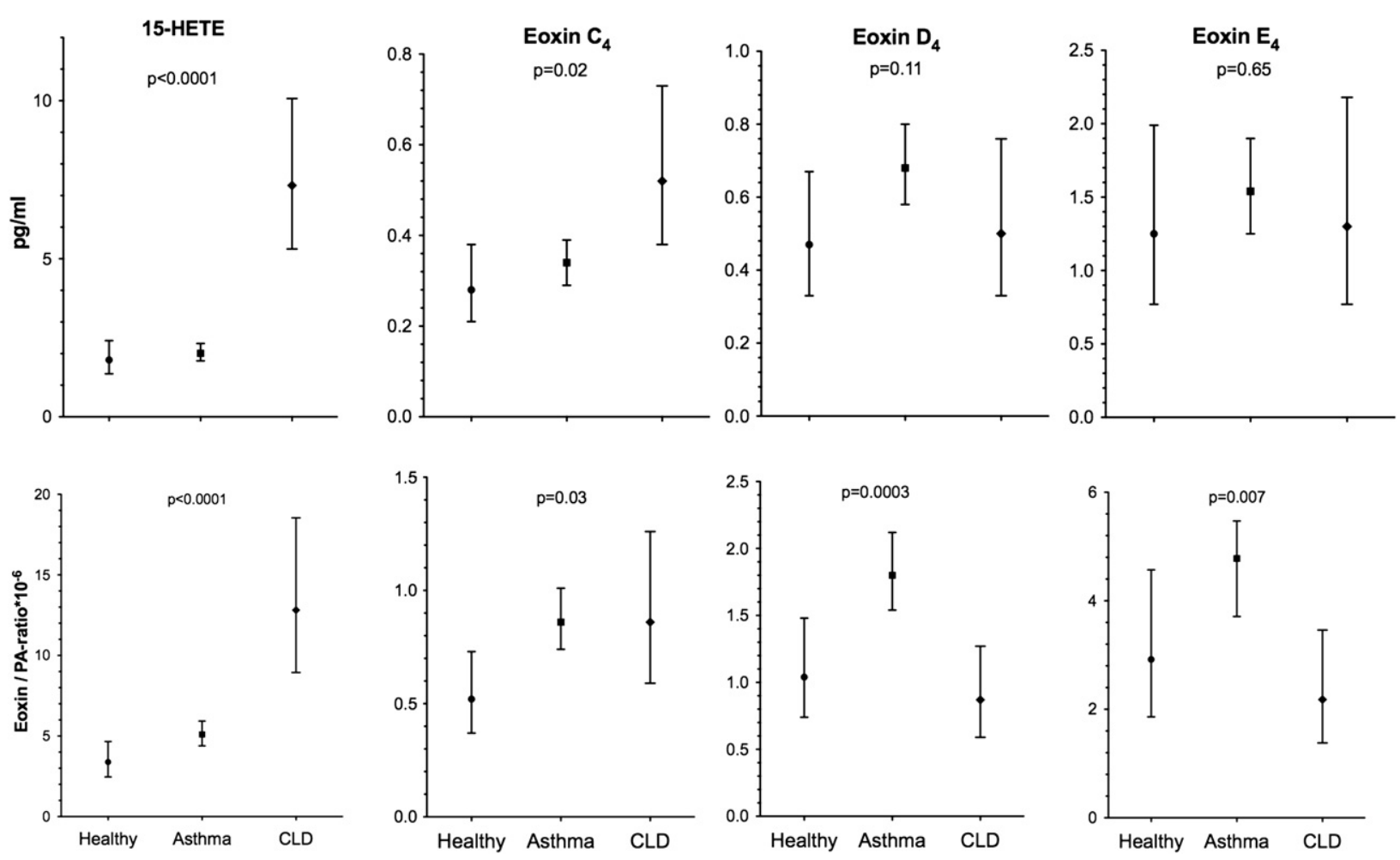

FIG 4. Least-squares means and $95 \%$ Cls of eicosanoids of the 15-LO pathway (15-HETE and eoxins $\mathrm{C}_{4}, \mathrm{D}_{4}$, and $\mathrm{E}_{4}$ ), both concentrations and PA ratios (eicosanoid/PA $\times 10^{-6}$ ).

A
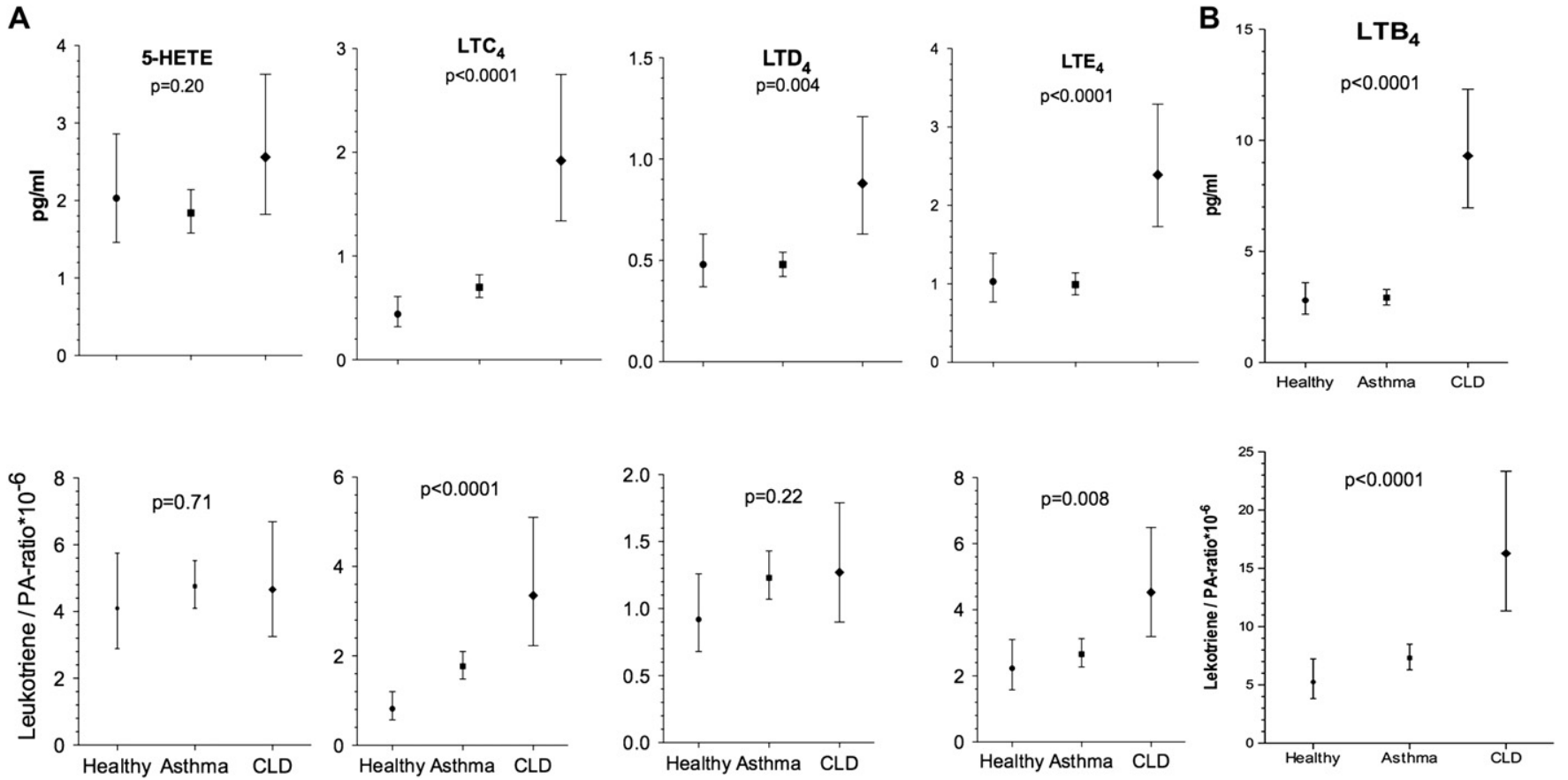

FIG 5. Least-squares means and $95 \% \mathrm{Cl}$ of eicosanoids of the $5-\mathrm{LO}$ pathway $\left(5-\mathrm{HETE}, \mathrm{LTC}_{4}, \mathrm{LTD}_{4}\right.$, and LTE ;

A) and $\mathrm{LTB}_{4}(\mathrm{~B})$, both concentrations and PA ratios (eicosanoid/PA $\times 10^{-6}$ ). 
TABLE II. Values (geometric means and 95\% Cls) of eicosanoids in EBC of healthy children and children with asthma and other chronic lung diseases: Concentrations (in picograms per milliliter) and adjusted PA ratios*

\begin{tabular}{|c|c|c|c|c|c|}
\hline Eicosanoid & Healthy subjects & Asthmatic subjects & $P$ value vs healthy children & Chronic lung disease & Overall $P$ value \\
\hline $\mathrm{pg} / \mathrm{mL}$ & $1.81(1.26-2.61)$ & $2.02(1.78-2.30)$ & .50 & $7.33(5.37-10.01)$ & $<.001$ \\
\hline $\mathrm{pg} / \mathrm{mL}$ & $0.28(0.22-0.35)$ & $0.34(0.29-0.40)$ & .22 & $0.49(0.36-0.67)$ & .03 \\
\hline Ratio & $0.52(0.40-0.68)$ & $0.86(0.73-1.03)$ & .009 & $0.86(0.63-1.19)$ & .03 \\
\hline \multicolumn{6}{|l|}{ Eoxin $\mathrm{D}_{4}$} \\
\hline \multicolumn{6}{|l|}{ Eoxin $E_{4}$} \\
\hline $\mathrm{pg} / \mathrm{mL}$ & $1.21(0.90-1.62)$ & $1.66(1.36-2.03)$ & .16 & $1.11(0.87-1.40)$ & .11 \\
\hline Ratio & $2.25(1.70-3.00)$ & $4.19(3.36-5.22)$ & .01 & $1.94(1.55-2.43)$ & .001 \\
\hline \multicolumn{6}{|l|}{ 5-HETE } \\
\hline $\mathrm{pg} / \mathrm{mL}$ & $1.69(1.24-2.31)$ & $1.75(1.51-2.02)$ & .85 & $2.35(1.62-3.42)$ & .27 \\
\hline Ratio & $3.17(2.39-4.20)$ & $4.42(3.75-5.21)$ & .08 & $4.12(3.05-5.57)$ & .19 \\
\hline $\mathrm{pg} / \mathrm{mL}$ & $0.49(0.37-0.66)$ & $0.49(0.43-0.56)$ & .97 & $0.73(0.58-0.92)$ & .054 \\
\hline Ratio & $0.92(0.66-1.28)$ & $1.24(1.06-1.44)$ & .11 & $1.27(1.03-1.58)$ & .22 \\
\hline \multicolumn{6}{|l|}{$\mathrm{LTE}_{4}$} \\
\hline $\mathrm{pg} / \mathrm{mL}$ & $1.11(0.83-1.50)$ & $0.98(0.87-1.11)$ & .42 & $1.84(1.41-2.40)$ & .001 \\
\hline Ratio & $2.08,(1.65-2.62)$ & $2.47(2.14-2.86)$ & .30 & $3.23(2.45-4.24)$ & .13 \\
\hline \multicolumn{6}{|l|}{$\mathrm{LTB}_{4}$} \\
\hline $\mathrm{pg} / \mathrm{mL}$ & $2.80(2.22-3.54)$ & $2.91(2.61-3.25)$ & .77 & $9.26(5.89-14.54)$ & $<.001$ \\
\hline Ratio & $5.24(3.91-7.04)$ & $7.33(6.33-8.50)$ & .05 & $16.22(9.90-26.60)$ & $<.001$ \\
\hline \multicolumn{6}{|l|}{ PA } \\
\hline $\mathrm{ng} / \mathrm{mL}$ & $535(433-660)$ & $395(361-433)$ & .006 & $570(461-705)$ & .001 \\
\hline
\end{tabular}

*Eicosanoid/PA ratio $\left(\times 10^{-6}\right)$.

The lack of significant associations between eoxin/PA and CysLT/PA ratios and asthma severity contrasts with previous pediatric studies ${ }^{3,6}$ and might be due to the phenotypic heterogeneity of asthma or possibly to the relatively small number with severe problematic asthma. Nevertheless, children with the highest eoxin levels all had asthma, the majority with severe disease, ICS/ LTRA use, or both, suggesting a potential role for eoxins in asthma severity.

Except for the inconsistent association between $\mathrm{LTB}_{4}$ and lung function $\left(\mathrm{FEV}_{1}, \mathrm{FVC}\right.$, and $\mathrm{FEV}_{1} / \mathrm{FVC}$ ratio) between $\mathrm{LTD}_{4}$ concentration and FVC and between 15-HETE/PA ratio and $\mathrm{FEF}_{25-75}$, prebronchodilator and postbronchodilator lung function were not associated with EBC eicosanoids, which is in line with other pediatric studies (data not shown). The positive association between BHR and $\mathrm{LTE}_{4}$ in EBC is supported by 1 pediatric study. ${ }^{29}$ Lack of association between eicosanoid ratios and $\mathrm{FE}_{\mathrm{NO}}$ is also in accordance with most, ${ }^{3,5,26}$ but not all, ${ }^{6}$ previous pediatric reports. Allergic sensitization was associated with increased $\mathrm{LTE}_{4}$ and $\mathrm{LTB}_{4}$ values only, supporting the suggestion that CysLTs (and eoxins) are less related to allergic sensitization than is $\mathrm{FE}_{\mathrm{NO}} \cdot{ }^{4}$ Small population size prevented subgroup analyses on other allergic traits.

Although anti-inflammatory treatment might confound associations between EBC eicosanoids, asthma status, and asthma severity, regular ICS use did not significantly affect eoxin/PA ratios in EBC. The association between ICS use and reduced $\mathrm{LTE}_{4}$ values is supported by some,${ }^{28,30}$ but not all, ${ }^{4}$ previous pediatric studies. On the other hand, the association between LTRA use and increased levels of both 5-LO and 15-LO pathways ( $\mathrm{LTE}_{4}$ and eoxin $\mathrm{E}_{4}$ ) in this population, selected based on criteria other than use of LTRAs, contrasts with previous reports on LTs. ${ }^{27,31,32}$ Because LTRAs were predominantly used in children also using regular ICSs, it might be a surrogate marker for increased asthma severity. In addition, one cannot exclude the possibility that LTRA use, previously shown to have a selective inhibitory effect on 5-LO in vitro, ${ }^{33}$ shifts eicosanoid production in the direction of the 15-LO pathway. More studies are required to elucidate this issue.

MS analysis in EBC is highly sensitive and superior to other assays, such as enzyme immunoassay. ${ }^{21,34}$ Because some of the observed variability in EBC solute concentrations might reflect differences in airway lining fluid dilution, adjusting for dilutions by using markers such as urea, cations, total protein, or in this case PA has been recommended. ${ }^{21,22,35}$ Interestingly, although PA was reasonably normally distributed among all samples, reanalysis stratified by healthy and asthmatic children demonstrated clear deviations from normality in the latter study group (decreasing PA concentrations with increasing asthma severity, see Table E3). Therefore a second control group (other chronic lung diseases) was included in the study, in which the distribution of PA concentrations was similar to that of healthy children. Although there is no consensus on what diluent indicator to use in EBC or whether this is necessary, the use of PA is supported by studies demonstrating a correlation between LT levels in EBC and BAL fluid only when adjusted values were calculated. ${ }^{36} \mathrm{PA}$ is a main constituent of lung surfactant, but the method of sample 
extraction and PA analysis implied measurement of the free fatty acid component only. The relatively constant plasma level of free fatty acid diffuses freely across biological membranes and proved, in our hands, more convenient than urea concentration. ${ }^{37}$ All EBC analyses were performed by a scientific team blinded to subject characteristics, thus reducing the possibility of interpretation bias. Without measurement of amylase concentration, salivary contamination of EBC cannot be ruled out, ${ }^{16}$ but the risk was minimized with swallowing and the use of a salivary trap. ${ }^{21}$

In conclusion, the results point to increased activity of the 15LO inflammatory pathway in childhood asthma. MS analyses of EBC demonstrate that increased eoxin levels accompany the increased 5-LO product $\mathrm{LTC}_{4}$ and are associated with BHR. These markers of the 15-LO pathway might represent a new therapeutic target for asthma treatment.

The research team, including Torill Tørres, Solveig Knutsen, Eli Schrøder, and Amund Riiser, assisted in data collection.

Clinical implications: The present study is the first to demonstrate an association between eoxins and asthma and BHR in children, potentially signifying a new therapeutic target for asthma treatment.

\section{REFERENCES}

1. Barnes PJ. Pathophysiology of asthma. Br J Clin Pharmacol 1996;42:3-10.

2. Drazen JM, Israel E, O'Byrne PM. Treatment of asthma with drugs modifying the leukotriene pathway. N Engl J Med 1999;340:197-206.

3. Csoma Z, Kharitonov SA, Balint B, Bush A, Wilson NM, Barnes PJ. Increased leukotrienes in exhaled breath condensate in childhood asthma. Am J Respir Crit Care Med 2002;166:1345-9.

4. Kielbasa B, Moeller A, Sanak M, Hamacher J, Hutterli M, Cmiel A, et al. Eicosanoids in exhaled breath condensates in the assessment of childhood asthma. Pediatr Allergy Immunol 2008;19:660-9.

5. Montuschi P, Martello S, Felli M, Mondino C, Barnes PJ, Chiarotti M. Liquid chromatography/mass spectrometry analysis of exhaled leukotriene B4 in asthmatic children. Respir Res 2005;6:119.

6. Zanconato S, Carraro S, Corradi M, Alinovi R, Pasquale MF, Piacentini G, et al. Leukotrienes and 8-isoprostane in exhaled breath condensate of children with stable and unstable asthma. J Allergy Clin Immunol 2004;113:257-63.

7. Profita M, Sala A, Riccobono L, Paterno A, Mirabella A, Bonanno A, et al. 15Lipoxygenase expression and 15(S)-hydroxyeicoisatetraenoic acid release and reincorporation in induced sputum of asthmatic subjects. J Allergy Clin Immunol 2000;105:711-6.

8. Liu C, Xu D, Liu L, Schain F, Brunnstrom A, Bjorkholm M, et al. 15-Lipoxygenase- 1 induces expression and release of chemokines in cultured human lung epithelial cells. Am J Physiol Lung Cell Mol Physiol 2009;297:L196-1203.

9. Chu HW, Balzar S, Westcott JY, Trudeau JB, Sun Y, Conrad DJ, et al. Expression and activation of 15-lipoxygenase pathway in severe asthma: relationship to eosinophilic phenotype and collagen deposition. Clin Exp Allergy 2002;32:1558-65.

10. Zhao J, Maskrey B, Balzar S, Chibana K, Mustovich A, Hu H, et al. Interleukin-13induced MUC5AC is regulated by 15-lipoxygenase 1 pathway in human bronchial epithelial cells. Am J Respir Crit Care Med 2009;179:782-90.

11. Krawiec ME, Westcott JY, Chu HW, Balzar S, Trudeau JB, Schwartz LB, et al. Persistent wheezing in very young children is associated with lower respiratory inflammation. Am J Respir Crit Care Med 2001;163:1338-43.

12. Feltenmark S, Gautam N, Brunnstrom A, Griffiths W, Backman L, Edenius C, et al Eoxins are proinflammatory arachidonic acid metabolites produced via the 15-lipoxygenase-1 pathway in human eosinophils and mast cells. Proc Natl Acad Sci U S A 2008;105:680-5.

13. Claesson HE. On the biosynthesis and biological role of eoxins and 15-lipoxygenase-1 in airway inflammation and Hodgkin lymphoma. Prostaglandins Other Lipid Mediat 2009;89:120-5.
14. Ono E, Mita H, Taniguchi M, Higashi N, Hasegawa M, Miyazaki E, et al. Concentration of 14,15-leukotriene C4 (eoxin C4) in bronchoalveolar lavage fluid. Clin Exp Allergy 2009;39:1348-52.

15. Kostikas K, Koutsokera A, Papiris S, Gourgoulianis KI, Loukides S. Exhaled breath condensate in patients with asthma: implications for application in clinical practice. Clin Exp Allergy 2008;38:557-65.

16. Kharitonov SA, Barnes PJ. Exhaled markers of pulmonary disease. Am J Respir Crit Care Med 2001;163:1693-722.

17. Sanak M, Kielbasa B, Bochenek G, Szczeklik A. Exhaled eicosanoids following oral aspirin challenge in asthmatic patients. Clin Exp Allergy 2004;34: 1899-904.

18. Bush A, Hedlin G, Carlsen KH, de Benedictis F, Lodrup-Carlsen K, Wilson N. Severe childhood asthma: a common international approach? Lancet 2008;372:1019-21.

19. Centers for Disease Control and Prevention. BMI calculator for child and teen; English version. Atlanta: Centers for Disease Control and Prevention; 2007.

20. Stanojevic S, Wade A, Stocks J, Hankinson J, Coates AL, Pan H, et al. Reference ranges for spirometry across all ages: a new approach. Am J Respir Crit Care Med 2008; 177:253-60

21. Horvath I, Hunt J, Barnes PJ, Alving K, Antczak A, Baraldi E, et al. Exhaled breath condensate: methodological recommendations and unresolved questions. Eur Respir J 2005;26:523-48.

22. Sanak M, Gielicz A, Nagraba K, Kaszuba M, Kumik J, Szczeklik A. Targeted eicosanoid lipidomics of exhaled breath condensate in healthy subjects. J Chromatogr B Analyt Technol Biomed Life Sci 2010;878:1796-800.

23. Andersson CK, Claesson HE, Rydell-Tormanen K, Swedmark S, Hallgren A, Erjefalt JS. Mice lacking 12/15-lipoxygenase have attenuated airway allergic inflammation and remodeling. Am J Respir Cell Mol Biol 2008;39 648-56.

24. Szefler SJ, Phillips BR, Martinez FD, Chinchilli VM, Lemanske RF, Strunk RC, et al. Characterization of within-subject responses to fluticasone and montelukast in childhood asthma. J Allergy Clin Immunol 2005;115:233-42.

25. Tantisira KG, Drazen JM. Genetics and pharmacogenetics of the leukotriene pathway. J Allergy Clin Immunol 2009;124:422-7.

26. Carraro S, Corradi M, Zanconato S, Alinovi R, Pasquale MF, Zacchello F, et al Exhaled breath condensate cysteinyl leukotrienes are increased in children with exercise-induced bronchoconstriction. J Allergy Clin Immunol 2005;115: 764-70.

27. Montuschi P, Mondino C, Koch P, Barnes PJ, Ciabattoni G. Effects of a leukotriene receptor antagonist on exhaled leukotriene $\mathrm{E}(4)$ and prostanoids in children with asthma. J Allergy Clin Immunol 2006;118:347-53.

28. Mondino C, Ciabattoni G, Koch P, Pistelli R, Trove A, Barnes PJ, et al. Effects of inhaled corticosteroids on exhaled leukotrienes and prostanoids in asthmatic children. J Allergy Clin Immunol 2004;114:761-7.

29. Shibata A, Katsunuma T, Tomikawa M, Tan A, Yuki K, Akashi K, et al. Increased leukotriene $\mathrm{E} 4$ in the exhaled breath condensate of children with mild asthma. Chest 2006;130:1718-22.

30. Steiss JO, Rudloff S, Landmann E, Ruckes-Nilges C, Zimmer KP, Lindemann H Effect of inhaled corticosteroid treatment on exhaled breath condensate leukotriene E(4) in children with mild asthma. Allergy Asthma Proc 2008;29:371-5.

31. Biernacki WA, Kharitonov SA, Biernacka HM, Barnes PJ. Effect of montelukast on exhaled leukotrienes and quality of life in asthmatic patients. Chest 2005; 128:1958-63.

32. Lex C, Zacharasiewicz A, Payne DN, Wilson NM, Nicholson AG, Kharitonov SA, et al. Exhaled breath condensate cysteinyl leukotrienes and airway remodeling in childhood asthma: a pilot study. Respir Res 2006;7:63.

33. Ramires R, Caiaffa MF, Tursi A, Haeggstrom JZ, Macchia L. Novel inhibitory effect on 5-lipoxygenase activity by the anti-asthma drug montelukast. Biochem Biophys Res Commun 2004;324:815-21.

34. Montuschi P. LC/MS/MS analysis of leukotriene B(4) and other eicosanoids in exhaled breath condensate for assessing lung inflammation. J Chromatogr B Analyt Technol Biomed Life Sci 2009;877:1272-80.

35. Hunt J. Exhaled breath condensate: an evolving tool for noninvasive evaluation of lung disease. J Allergy Clin Immunol 2002;110:28-34.

36. Ono E, Mita H, Taniguchi M, Higashi N, Tsuburai T, Miyazaki E, et al. Comparison of cysteinyl leukotriene concentrations between exhaled breath condensate and bronchoalveolar lavage fluid. Clin Exp Allergy 2008;38:1866-74.

37. Esther CR Jr, Boysen G, Olsen BM, Collins LB, Ghio AJ, Swenberg JW, et al. Mass spectrometric analysis of biomarkers and dilution markers in exhaled breath condensate reveals elevated purines in asthma and cystic fibrosis. Am J Physiol Lung Cell Mol Physiol 2009;296:L987-93. 


\section{METHODS}

\section{Recruitment and study population}

Children with a registered specialist's diagnosis of asthma were identified and were eligible for inclusion to the study. Patients' charts from 2 university clinics (Ullevål and Rikshospitalet) and 2 county hospitals (Lillehammer and Fredrikstad) were systematically reviewed, identifying patients receiving high-dose ICSs ( $\geq 800 \mu \mathrm{g}$ of budesonide equivalent), oral steroid therapy, or both within the preceding year. A corresponding number of age-matched but otherwise unselected asthmatic control subjects were identified from the remaining outpatient population. Age-matched nonasthmatic control subjects with a registered address in Oslo were randomly identified from the Norwegian National Registry. In children with mildto-moderate asthma overall, use of ICS treatment (intermittent or regular) was reported in $93 \%$, use of LTRAs in $23 \%$, and use of long-acting inhaled $\beta_{2}$-agonists in $55 \%$.

Participants were classified as having current rhinoconjunctivitis if they had at least 1 major and 1 minor criterion (other than a major criterion) within the last 12 months. Major criteria were a doctor's diagnosis of hay fever or at least 2 of the following: rhinorrhea, itchy/running eyes, nasal congestion, or sneezing. Minor criteria (at least 1 of the following) were (1) rhinorrhea, itchy/ running eyes, nasal congestion, or sneezing or (2) treatments for eye/nose symptoms: local or systemic antihistamines, local or systemic corticosteroids, sodium cromoglycate, LT antagonists, and immunotherapy.

\section{Methods}

Sample preparation. After thawing, the $\mathrm{pH}$ of the EBC was adjusted to 3.5 by using acetic acid $(2 \mu \mathrm{L})$, and internal deuterated standards, comprising 5-HETE-d $\mathrm{d}_{8}, 15-\mathrm{HETE}-\mathrm{d}_{8}, \mathrm{LTD}_{4}-\mathrm{d}_{5}, \mathrm{LTE}_{4}-\mathrm{d}_{3}, \mathrm{LTB}_{4}-\mathrm{d}_{4}(0.5 \mathrm{ng})$, and PA- $\mathrm{d}_{4}(40 \mathrm{ng})$ in methanol, were added. The sample was extracted twice with $1 \mathrm{~mL}$ of tertiary butyl methyl ether. Organic phases were combined and evaporated under nitrogen at room temperature. Residues were dissolved in methanol $(60 \mu \mathrm{L})$ and immediately used for further analyses.

\section{Example of eicosanoid measurements}

For more information, see Fig 2. Two deuterated internal standards $\left(\mathrm{LTD}_{4}-\mathrm{d}_{5}\right.$ and $\mathrm{LTE}_{4}-\mathrm{d}_{3}, 0.5 \mathrm{ng}$ each) were added to $1 \mathrm{~mL}$ of the condensate. Eoxins $\mathrm{C}_{4}, \mathrm{D}_{4}$, and $\mathrm{E}_{4}$ and CysLTs $\mathrm{LTC}_{4}$ and $\mathrm{LTD}_{4}-\mathrm{d}_{5}$ were measured by using the positive ionization mode and multiple reaction monitoring (eoxins: 626.4 $>205.3$, 497.4>205.2, and 440.2>205.2 M/z; CysLTs: $626.4>308.3$ and 502.4>199.4 $\mathrm{M} / \mathrm{z})$. Native $\mathrm{LTE}_{4}$ was measured by using negative ionization and fragmentation of ions $(438.4>333.3 \mathrm{M} / \mathrm{z})$, whereas $\mathrm{LTE}_{4}-\mathrm{d}_{3}$ standard was measured by using both positive and negative ionization modes (443.4>192.4 and 441.4>336.2 $\mathrm{M} / \mathrm{z}$ ). Vertical scale of individual spectrograms was changed to relative intensity of counts per second.

Lung function was measured based on forced expiratory flow-volume curves using a Sensor Medics Vmax 229 series with Autobox (VIASYS Healthcare, Inc, Yorba Linda, Calif), according to American Thoracic Society/ European Respiratory Society guidelines. ${ }^{\text {E1 }}$ Reported values included FEV and the $\mathrm{FEV}_{1} / \mathrm{FVC}$ ratio, both expressed as percent predicted according to recently published reference algorithms by Stanojevic et al. ${ }^{\mathrm{E} 2}$

BHR was determined based on $\mathrm{PD}_{20}$ methacholine by using a Spira nebulizer (Spira Respiratory Care Centre, Hämeenlinna, Finland). ${ }^{\mathrm{E} 3}$ Two patients were excluded from methacholine provocation because of a baseline $\mathrm{FEV}_{1}$ of less than 70\%, and 15 BHR tests, mostly in children aged 6 to 7 years, were incomplete or discarded because of unstable lung function technique. BHR was defined as $\mathrm{PD}_{20}$ of $8 \mu \mathrm{mol}$ or less methacholine. The dose-response slope $_{\text {methacholine }}$ was determined by using the following formula: Percentage decrease in $\mathrm{FEV}_{1} /$ Cumulated dose methacholine (in micromoles). ${ }^{\mathrm{E} 4}$

Skin prick tests to 13 common allergens were performed with Soluprick allergens (ALK-Abelló, Hørsholm, Denmark). Wheal diameters of $3 \mathrm{~mm}$ or more larger than those elicited by the negative control (isotonic saline) were considered positive. The following allergens were used: domestic mite (Dermatophagoides pteronyssinus); dog, cat, and rabbit dander; birch, timothy, and mugwort pollen; Cladosporium herbarum; Alternaria alternata; egg white; milk; peanut; and codfish.
Short-acting inhaled $\beta_{2}$-agonists were withheld for 8 hours, and longacting inhaled $\beta_{2}$-agonists/LTRAs were withheld for 48 hours before lung function measurements and methacholine bronchial challenge tests, whereas systemic antihistamines were withheld for 5 days before skin prick testing.

$\mathrm{FE}_{\mathrm{NO}}$ was recorded before lung function measurement by using the Eco Medics CLD 88 Exhalyzer (Eco Medics AG, Duernten, Switzerland), according to American Thoracic Society/European Respiratory Society recommendations. ${ }^{\mathrm{E} 5}$

Serum ECP and total IgE levels were analyzed by using a fluoroenzyme immunoassay, according to the manufacturer's recommendations (ImmunoCAP; Phadia AB, Uppsala, Sweden).

\section{RESULTS \\ Eicosanoids and medication in children with asthma}

Regular use of ICSs was not significantly associated with eicosanoid levels, except a lower $\mathrm{LTE}_{4}$ concentration seen in children receiving ICS treatment $(0.9 \mathrm{vs} 1.2 \mathrm{pg} / \mathrm{mL}, P=.02)$.

Asthmatic children receiving LTRAs had higher eicosanoid levels than those without, with differences reaching statistical significance for eoxin $\mathrm{E}_{4}(2.1 \mathrm{vs} 1.4 \mathrm{pg} / \mathrm{mL}, P=.03)$ and 5-HETE (2.2 vs $1.6 \mathrm{pg} / \mathrm{mL}, P=.04$ ) concentrations, as well as eoxin $\mathrm{E}_{4} / \mathrm{PA}$ (5.9 vs $\left.3.5 \times 10^{-6}, P=.02\right), 5$-HETE/PA $\left(6.0\right.$ vs $3.7 \times 10^{-6}, P=$ $.002)$, and $\mathrm{LTE}_{4} / \mathrm{PA}$ ratios (3.0 vs $\left.2.2 \times 10^{-6}, P=.05\right)$. When this analysis was limited to patients with regular ICS use, differences in eicosanoid levels in patients using versus those not using LTRAs were less pronounced, reaching significance for 5-HETE/PA ratios only (5.9 vs $\left.3.8 \times 10^{-6}, P=.03\right)$.

\section{ANOVA analyses of eicosanoid concentrations and eicosanoid/PA ratios in the 3 groups of children (healthy children, asthmatic children, and children with other chronic lung diseases)}

Eoxin concentrations. Compared with healthy children, children with other chronic lung diseases had significantly higher concentrations of eoxin $\mathrm{C}_{4}(P=.03)$ and 15-HETE $(P<$ $.001)$ only. 15-HETE concentrations were significantly higher in children with other chronic lung diseases compared with asthmatic children, whereas there was no significant difference for eoxin $\mathrm{C}_{4}$.

LT concentrations. The LT concentrations demonstrated that compared with healthy children, only LTC $_{4}$ concentrations were increased in asthmatic children, whereas in children with other chronic lung diseases, $\operatorname{LTC}_{4}(P<.001), \operatorname{LTE}_{4}(P=.03)$, and $\mathrm{LTB}_{4}(P<.001)$ concentrations were significantly increased. Compared with asthmatic children, children with chronic lung disease had significantly higher $\operatorname{LTC}_{4}(P<.001), \operatorname{LTD}_{4}(P=$ $.045), \operatorname{LTE}_{4}(P<.001)$, and $\mathrm{LTB}_{4}(P<.001)$ concentrations.

Eicosanoid/PA ratios. Asthma was associated with significantly increased eoxin $\mathrm{C}_{4} / \mathrm{PA}$, eoxin $\mathrm{D}_{4} / \mathrm{PA}$, and eoxin $\mathrm{E}_{4} / \mathrm{PA}$ ratios, whereas the 15-HETE/PA ratio only was significantly higher in children with other chronic lung diseases compared with healthy children. Children with asthma had significantly higher eoxin $\mathrm{D}_{4} /$ $\mathrm{PA}$ and eoxin $\mathrm{E}_{4} / \mathrm{PA}$ ratios but significantly lower 15-HETE/PA ratios compared with patients with chronic lung disease.

Asthmatic children had significantly higher $\mathrm{LTC}_{4} / \mathrm{PA}$ ratios, whereas children with other chronic lung diseases had significantly higher $\mathrm{LTC}_{4} / \mathrm{PA}$ and $\mathrm{LTB}_{4} / \mathrm{PA}$ ratios compared with healthy children. Compared with children with other chronic lung diseases, asthmatic children had significantly lower $\mathrm{LTC}_{4} /$ $\mathrm{PA}$ and $\mathrm{LTB}_{4} / \mathrm{PA}$ ratios. 


\section{REFERENCES}

E1. Miller MR, Hankinson J, Brusasco V, Burgos F, Casaburi R, Coates A, et al. Standardisation of spirometry. Eur Respir J 2005;26:319-38.

E2. Stanojevic S, Wade A, Stocks J, Hankinson J, Coates AL, Pan H, et al. Reference ranges for spirometry across all ages: a new approach. Am J Respir Crit Care Med 2008;177:253-60.

E3. Nieminen MM, Lahdensuo A, Kellomaeki L, Karvonen J, Muittari A. Methacholine bronchial challenge using a dosimeter with controlled tidal breathing. Thorax 1988;43:896-900.
E4. O'Connor G, Sparrow D, Taylor D, Segal M, Weiss S. Analysis of dose-response curves to methacholine. An approach suitable for population studies. Am Rev Respir Dis $1987 ; 136: 1412-7$.

E5. ATS/ERS recommendations for standardized procedures for the online and offline measurement of exhaled lower respiratory nitric oxide and nasal nitric oxide, 2005. Am J Respir Crit Care Med 2005;171:912-30.

E6. Centers for Disease Control and Prevention. BMI calculator for child and teen; English version. Atlanta: Centers for Disease Control and Prevention; 2007. 


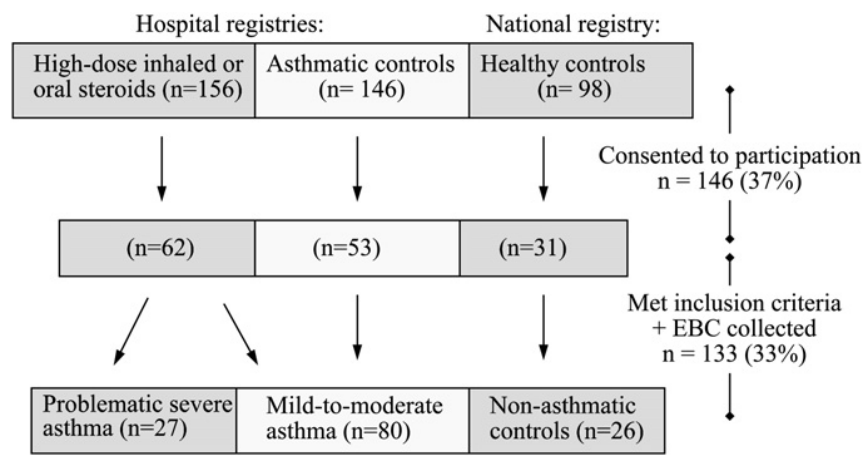

FIG E1. Flow chart of the inclusion algorithm of the $131 \mathrm{SEARCH}$ children. 

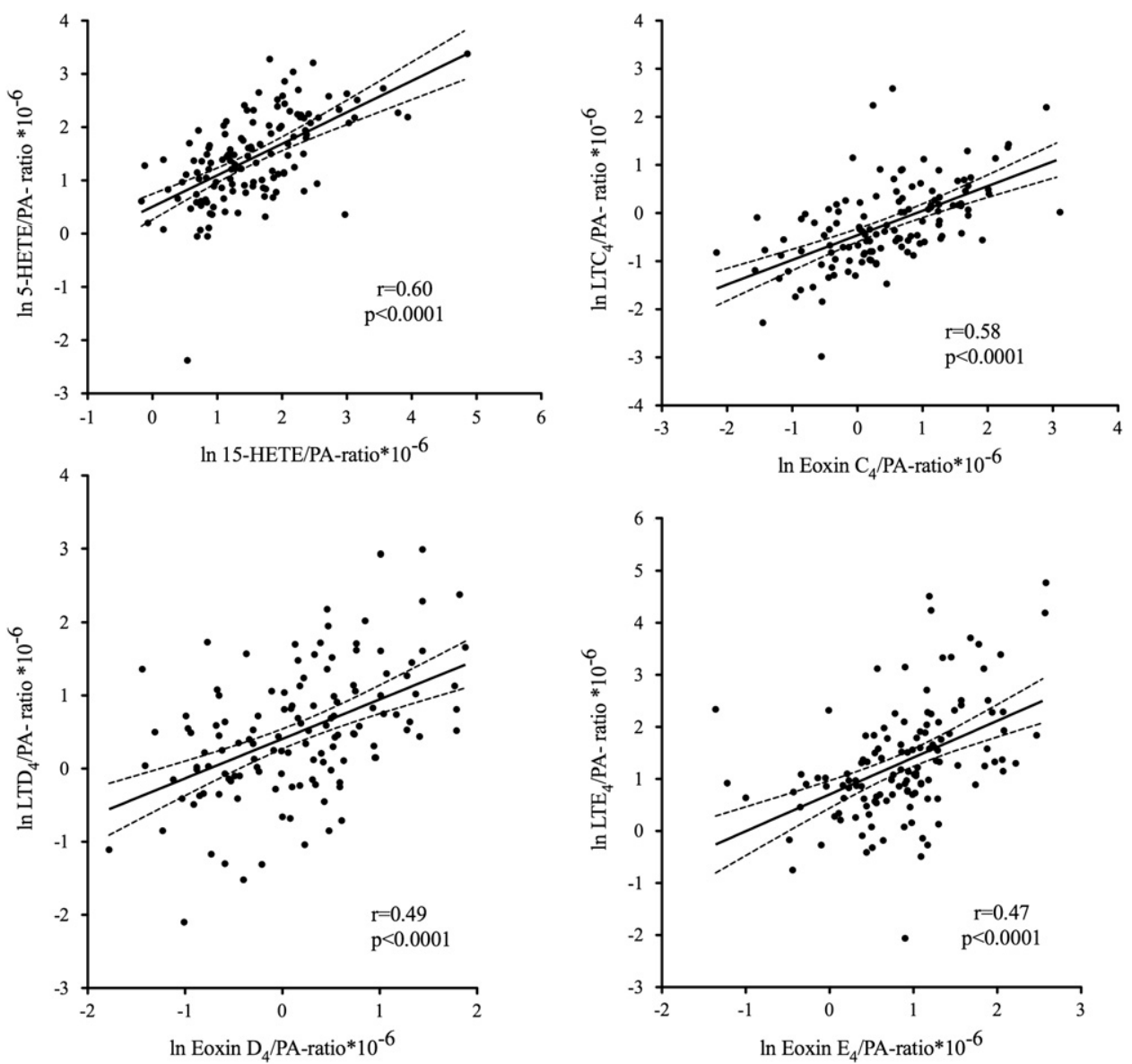

FIG E2. Significant correlations between eoxin $\mathrm{C}_{4} / \mathrm{PA}$, eoxin $\mathrm{D}_{4} / \mathrm{PA}$, eoxin $\mathrm{E}_{4} / \mathrm{PA}$, and 15-HETE/PA ratios $\left(\right.$ eoxin/PA $\times 10^{-6}$ ) with the respective $\mathrm{LTC}_{4} / \mathrm{PA}, \mathrm{LTD}_{4} / \mathrm{PA}, \mathrm{LTE} / \mathrm{PA}$, and 5 - $\mathrm{HETE} / \mathrm{PA}$ ratios $\left(\mathrm{LT} / \mathrm{PA} \times 10^{-6}\right)$ in the SEARCH children $(n=131)$. Ratios are given as natural logarithms, and the Pearson test was used for correlation analyses (correlation lines with $95 \% \mathrm{Cls}$ ). 

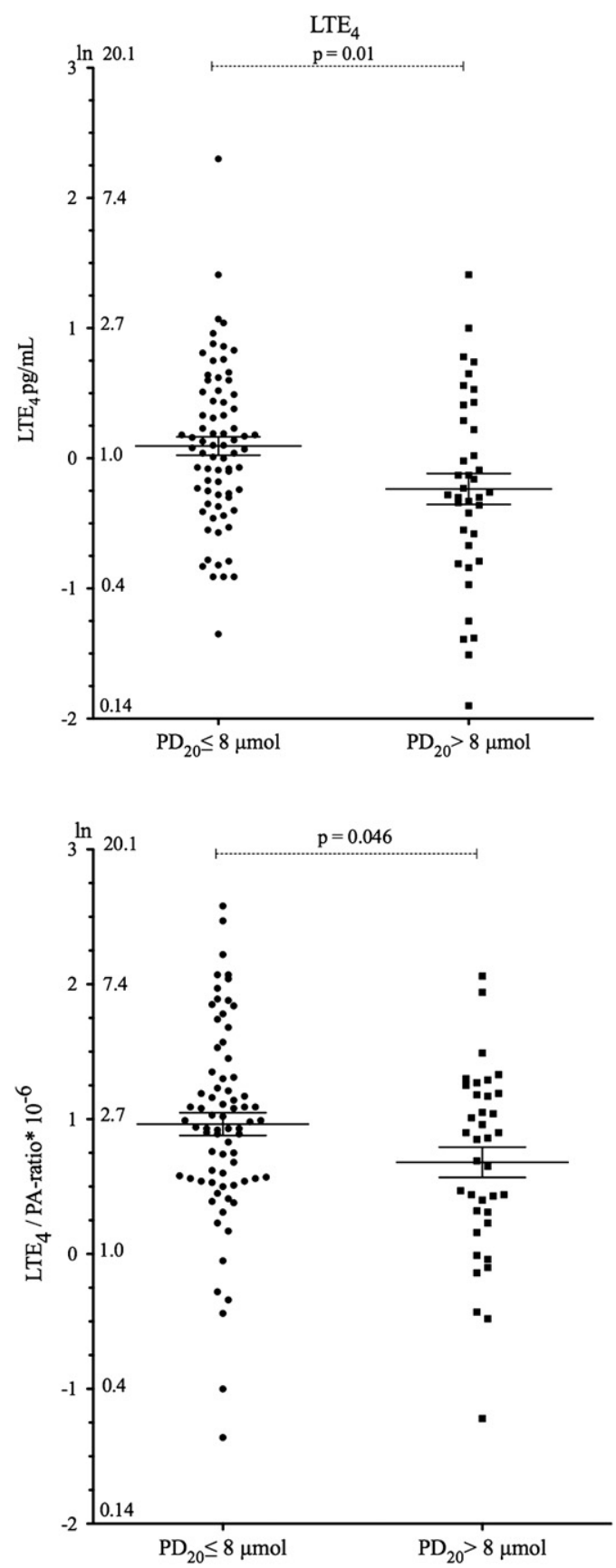

FIG E3. $\mathrm{LTE}_{4}$ concentrations and PA ratios (eicosanoid/PA $\times 10^{-6}$ ) in children with $\mathrm{BHR}$ to methacholine $\left(\mathrm{PD}_{20}, \leq 8 \mu \mathrm{mol}\right.$ methacholine). Values are given as natural logarithms and back-transformed values (geometric means with $95 \% \mathrm{Cls}$ ). 

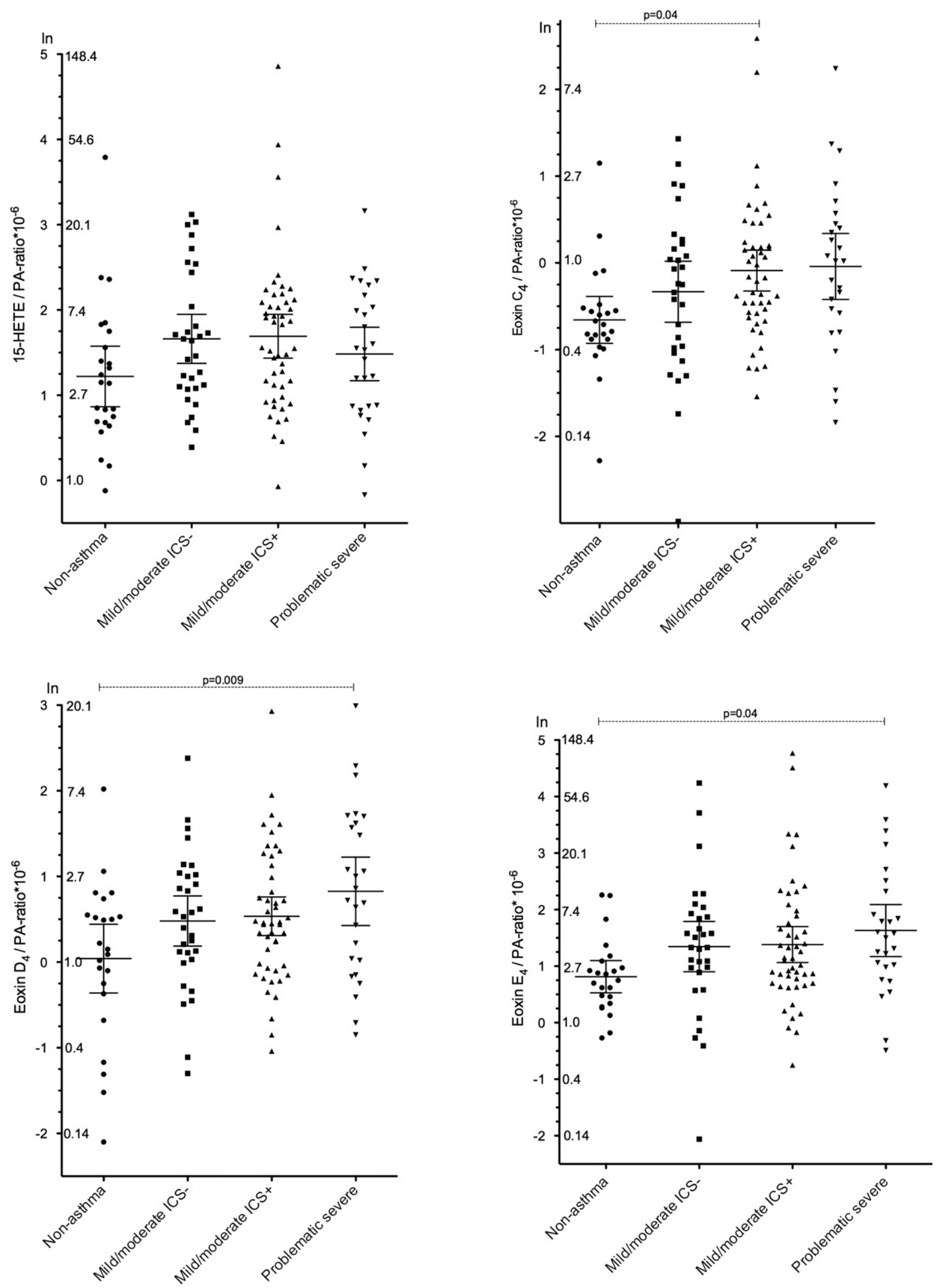

FIG E4. Eoxin/PA and 15-HETE/PA ratios (eoxin/PA $\times 10^{-6}$ ) are demonstrated in children with problematic severe asthma, children mild-to-moderate asthma with or without regular ICS use, and healthy nonasthmatic children. Values are given as natural logarithms and back-transformed values (geometric means with $95 \% \mathrm{Cls}$ ). Group comparisons by means of 1-way ANOVA and $P$ values are given for pairwise multiple comparisons by using the Tukey test. 
TABLE E1. Patients' characteristics and clinical data of the asthmatic subgroups of children

\section{Mild-to moderate asthma}

No regular ICSs $(n=31)$

Female subjects, n $(\%)$

Age (minimum-maximum; y)

BMI percentile (SD)

ICS use, = intermittent, $\mathrm{n}^{*}$

ICS use $(\mu \mathrm{g})$ regular, $\mathrm{n}(\%)$

$<400$
$400-800$

$\geq 800$

LTRA, n (\%)*

LABA, n (\%)*

$\mathrm{FEV}_{1}(\%$ predicted $[\mathrm{SD}]) \dagger$

$\mathrm{FEV}_{1} / \mathrm{FVC}$ ratio (SD)

$\mathrm{FE}_{\mathrm{NO}} \mathrm{ppb}$ (geometric mean)

$\mathrm{PD}_{20} \leq 8 \mu \mathrm{mol}(\%)$

SPT, any positive, n (\%)

Total IgE kU/L (geometric mean)

ECP $\mu \mathrm{mol}$ (geometric mean)

Regular ICSs $(n=49)$

$11(35$
$10.8(6-17)$
$51(28)$

$16(33) \ddagger$

$10.6(6-18)$

49 (27)

0

$16(33)$

21 (43)

$12(24)$

$13(27) \S$

$33(67) \S$

$11(36) \S$

$93(15)$

$0.85(0.08)$

$18.2(12.9-25.8) \div$

$21(78)+$

$21(68) \ddagger$

$233(114-475)$

$13.0(9.4-17.8)$
$98(13)$

$0.87(0.06) \S$

$11.1(7.9-15.8)$

$31(69) \$$

$35(71) \ddagger$

$194(120-315)$

$16.4(12.5-21.6) \ddagger$

Problematic severe asthma $(n=27)$

$8(30)$ :

$11.5(6-17)$

54 (33)

0

0

$27(100)$

20 (74)

$25(93)$

$92(17)$

$0.82(0.08) \ddagger$

$15.2(9.9-23.1)$

$16(70)$

$17(63) \ddagger$

$416(191-906) \ddagger$

$17.5(11.9-25.7)$

Results are represented as means (95\% CIs) or counts unless otherwise stated. Significance figures are derived by using ANOVA among the 4 populations for continuous variables or $\chi^{2}$ tests for proportions.

$B M I$, Body mass index ${ }^{\mathrm{E} 6} ; S P T$, skin prick test.

*Antiasthma medication within 12 months preceding inclusion to the study and ICS dosage referring to budesonide equivalent daily dose. Intermittent ICS use implies ICS use of short duration during asthma exacerbations and not within 2 weeks before inclusion.

$\dagger$ Reference values by Stanojevic et al. ${ }^{\mathrm{E} 2}$

$\ddagger$ Significant differences $(P<.05)$ versus healthy subjects.

§Significant difference $(P<.05)$ versus children with problematic severe asthma. 
TABLE E2. Correlations between eoxins $\mathrm{C}_{4}, \mathrm{D}_{4}$, and $\mathrm{E}_{4}$ and 15-HETE concentrations and PA ratios (eoxin/PA $\times 10^{-6}$ ) with the respective $\mathrm{LTC}_{4}, \mathrm{LTD}_{4}, \mathrm{LTE}_{4}$, and 5-HETE concentrations and PA ratios in the SEARCH children $(\mathrm{n}=131)$

Disease groups

Healthy children

Children with mild-to-moderate asthma, ICS -

Children with mild-to-moderate asthma, ICS+

Children with problematic severe asthma

Children with chronic lung disease
Eoxin vs LT

Eoxin $\mathrm{C}_{4} / \mathrm{LTC}_{4}$

Eoxin $\mathrm{D}_{4} / \mathrm{LTD}_{4}$

Eoxin $\mathrm{E}_{4} / \mathrm{LTE}_{4}$

15-HETE/5-HETE

Eoxin $\mathrm{C}_{4} / \mathrm{LTC}_{4}$

Eoxin $\mathrm{D}_{4} / \mathrm{LTD}_{4}$

Eoxin $\mathrm{E}_{4} / \mathrm{LTE}_{4}$

15-HETE/5-HETE

Eoxin $\mathrm{C}_{4} / \mathrm{LTC}_{4}$

Eoxin $\mathrm{D}_{4} / \mathrm{LTD}_{4}$

Eoxin $\mathrm{E}_{4} / \mathrm{LTE}_{4}$

15-HETE/5-HETE

Eoxin $\mathrm{C}_{4} / \mathrm{LTC}_{4}$

Eoxin $\mathrm{D}_{4} / \mathrm{LTD}_{4}$

Eoxin $\mathrm{E}_{4} / \mathrm{LTE}_{4}$

15-HETE/5-HETE

Eoxin $\mathrm{C}_{4} / \mathrm{LTC}_{4}$

Eoxin $\mathrm{D}_{4} / \mathrm{LTD}_{4}$

Eoxin $\mathrm{E}_{4} / \mathrm{LTE}_{4}$

15-HETE/5-HETE
Coefficient* ${ }^{*}(\mathrm{gg} / \mathrm{mL}) \dagger$

$$
r=0.50
$$

$r=0.64$

$r=0.34$

$\rho=0.59$

$r=0.53$

$r=0.34$

$\rho=0.37$

$\rho=0.37$

$r=0.49$
$\rho=0.48$

\begin{tabular}{l}
$\boldsymbol{P}$ value \\
NS \\
NS \\
NS \\
NS \\
.006 \\
$<.001$ \\
.02 \\
$<.001$ \\
$<.001$ \\
NS \\
.02 \\
.009 \\
NS \\
NS \\
NS \\
NS \\
NS \\
NS \\
.03 \\
.04 \\
\hline
\end{tabular}

Coefficient ${ }^{*}$ ratio $\ddagger$

$P$ value NS

$r=0.43$ .04

NS

$\rho=0.46$

$r=0.71$

$r=0.80$

$r=0.36$

$\rho=0.69$

$r=0.64$

$r=0.76$

$r=0.55$

$\rho=0.62$

$r=0.44$

$r=0.40$

$r=0.57$

$\rho=0.51$

.02
$<.001$

$<.001$

.05

$<.001$

$<.001$

$<.001$

$<.001$

$<.001$

.03

.04

.002

.007

NS

NS

.03

$r=0.49$

.04

$N S$, not significant.

*Correlation coefficients: Pearson $r$ and Spearman $\rho$.

$\nmid$ Correlation between eicosanoid concentrations (picograms per milliliter).

‡Correlation between eicosanoid/PA ratios $\times 10^{-6}$. 
TABLE E3. Values of eicosanoids in EBC of children within subgroups of asthma: Concentrations (in picograms per milliliter) and PA ratios*

\begin{tabular}{|c|c|c|c|c|c|}
\hline Eicosanoid & Healthy & Mild-to-moderate asthma, ICS- & Mild-to-moderate asthma, ICS+ & Severe asthma & $P$ value* \\
\hline $\mathrm{pg} / \mathrm{mL}$ & $1.81(1.26-2.61)$ & $2.19(1.76-2.73)$ & $2.19(1.81-2.66)$ & $1.59(1.20-2.10)$ & .20 \\
\hline Ratio & $3.39(2.37-4.84)$ & $5.27(3.95-7.02)$ & $5.43(4.20-7.01)$ & $4.41(3.23-6.04)$ & .13 \\
\hline \multicolumn{6}{|l|}{ Eoxin $\mathrm{C}_{4}$} \\
\hline $\mathrm{pg} / \mathrm{mL}$ & $0.28(0.22-0.35)$ & $0.30(0.22-0.39)$ & $0.37(0.30-0.45)$ & $0.35(0.24-0.49)$ & .36 \\
\hline Ratio & $0.52(0.40-0.68)$ & $0.72(0.50-1.02)$ & $0.93(0.73-1.17)$ & $0.95(0.65-1.39)$ & .032 \\
\hline \multicolumn{6}{|l|}{ Eoxin $\mathrm{D}_{4}$} \\
\hline \multicolumn{6}{|l|}{ Eoxin $\mathrm{E}_{4}$} \\
\hline $\mathrm{pg} / \mathrm{mL}$ & $1.21(0.90-1.62)$ & $1.60(1.02-2.49)$ & $1.61(1.22-2.12)$ & $1.86(1.26-2.76)$ & .49 \\
\hline Ratio & $2.25(1.70-3.00)$ & $3.84(2.47-5.99)$ & $3.98(2.90-5.48)$ & $5.10(3.22-8.08)$ & .06 \\
\hline \multicolumn{6}{|l|}{ 5-HETE } \\
\hline $\mathrm{pg} / \mathrm{mL}$ & $1.69(1.24-2.31)$ & $1.65(1.24-2.21)$ & $1.89(1.58-2.26)$ & $1.61(1.09-2.38)$ & .80 \\
\hline Ratio & $3.17(2.39-4.20)$ & $3.98(2.89-5.49)$ & $4.68(3.76-5.83)$ & $4.48(3.00-6.71)$ & .28 \\
\hline $\mathrm{pg} / \mathrm{mL}$ & $0.49(0.37-0.66)$ & $0.57(0.44-0.75)$ & $0.51(0.43-0.61)$ & $0.38(0.29-0.50)$ & .14 \\
\hline Ratio & $0.92(0.66-1.28)$ & $1.37(0.99-1.91)$ & $1.26(1.02-1.56)$ & $1.04(0.77-1.42)$ & .23 \\
\hline \multicolumn{6}{|l|}{$\mathrm{LTE}_{4}$} \\
\hline $\mathrm{pg} / \mathrm{mL}$ & $1.11(0.83-1.50)$ & $1.23(0.98-1.56)$ & $0.89(0.73-1.06)$ & $0.93(0.72-1.19)$ & .11 \\
\hline Ratio & $2.08(1.65-2.62)$ & $2.97(2.32-3.80)$ & $2.17(1.71-2.76)$ & $2.54(1.94-3.31)$ & .20 \\
\hline \multicolumn{6}{|l|}{$\mathrm{LTB}_{4}$} \\
\hline $\mathrm{pg} / \mathrm{mL}$ & $2.80(2.22-3.54)$ & $2.81(2.22-3.57)$ & $3.10(2.62-3.67)$ & $2.70(2.25-3.23)$ & .74 \\
\hline Ratio & $5.24(3.91-7.04)$ & $6.77(4.88-9.39)$ & $7.67(6.13-9.61)$ & $7.39(5.86-9.32)$ & .23 \\
\hline \multicolumn{6}{|l|}{ PA } \\
\hline $\mathrm{ng} / \mathrm{mL}$ & $535(433-660)$ & $415(348-496)$ & $404(350-466)$ & $360(307-422)$ & .03 \\
\hline
\end{tabular}

*Eicosanoid/PA ratio $\left(\times 10^{-6}\right)$. 